\title{
Spatial Dynamics of Lyme Disease: A Review
}

\author{
Mary E. Killilea, ${ }^{1}$ Andrea Swei, ${ }^{2}$ Robert S. Lane, ${ }^{3}$ Cheryl J. Briggs,${ }^{4}$ Richard S. Ostfeld ${ }^{1}$ \\ ${ }^{1}$ Cary Institute of Ecosystem Studies, PO Box AB/2801, Sharon Turnpike, Millbrook, NY 12545-0129 \\ ${ }^{2}$ Department of Integrative Biology, University of California, Berkeley, CA \\ ${ }^{3}$ Department of Environmental Science, Policy, and Management, University of California, Berkeley, CA \\ ${ }^{4}$ Department of Ecology, Evolution, and Marine Biology, University of California, Santa Barbara, CA
}

\begin{abstract}
Lyme disease (LD), the most frequently reported vector-borne disease in the United States, requires that humans, infected vector ticks, and infected hosts all occur in close spatial proximity. Understanding the spatial dynamics of LD requires an understanding of the spatial determinants of each of these organisms. We review the literature on spatial patterns and environmental correlates of human cases of LD and the vector ticks, Ixodes scapularis in the northeastern and midwestern United States and Ixodes pacificus in the western United States. The results of this review highlight a need for a more standardized and comprehensive approach to studying the spatial dynamics of the LD system. Specifically, we found that the only environmental variable consistently associated with increased LD risk and incidence was the presence of forests. However, the reasons why some forests are associated with higher risk and incidence than others are still poorly understood. We suspect that the discordance among studies is due, in part, to the rapid developments in both conceptual and technological aspects of spatial ecology hastening the obsolescence of earlier approaches. Significant progress in identifying the determinants of spatial variation in LD risk and incidence requires that: (1) existing knowledge of the biology of the individual components of each LD system is utilized in the development of spatial models; (2) spatial data are collected over longer periods of time; (3) data collection and analysis among regions are more standardized; and (4) the effect of the same environmental variables is tested at multiple spatial scales.
\end{abstract}

Keywords: Lyme disease, Ixodes scapularis, Ixodes pacificus, spatial dynamics, landscape epidemiology, disease ecology

\section{INTRODUCTION}

Pathogen transmission is an inherently spatial process, requiring that a susceptible host encounters an infected host, an infected vector, or an environmental reservoir, depending on the pathogens. The probability of transmis-

Correspondence to: Mary E. Killilea, e-mail: killileam@ecostudies.org sion declines rapidly with increasing distance between the susceptible host and the pathogen source. Consequently, the factors that affect the spatial distribution of hosts, vectors, and pathogens in nature are fundamental to the transmission and thus the dynamics and patterns of disease. Ecologists and epidemiologists are increasingly focusing on the causes of spatial variation in risk and incidence of vector-borne and zoonotic diseases (reviewed in Ostfeld et al., 2005). 
Lyme disease (LD), the most frequently reported vector-borne disease in the United States (Orloski et al., 2000; CDC, 2007) and Europe (O’Connell et al., 1998, as referenced in Dennis and Hayes, 2002), is unevenly distributed at every spatial scale that has been explored. For example, in North America, the vast majority of cases occur in the northeastern part of the United States and southeastern Canada, the upper midwestern United States, and coastal central/northern California (Orloski et al., 2000). Even within these endemic zones, there is a great deal of variation, e.g., among counties within these zones, among local communities within counties, and among households within local communities (Glavanakov et al., 2001; Chen et al., 2005; Waller et al., 2007).

All vector-borne zoonotic diseases require the cooccurrence of a pathogen, a vector, one or more reservoir hosts, and the human victim. Lyme disease in North America is caused by the spirochete bacterium, Borrelia burgdorferi, which is vectored between hosts by Ixodes scapularis in eastern and central regions and Ixodes pacificus in the west. There are many potential reservoir hosts, mostly small mammals and birds, but the dominant hosts are rodents (e.g., white-footed mice, Peromyscus leucopus; eastern chipmunks, Tamias striatus; western gray squirrels, Sciurus griseus; and dusky-footed woodrats, Neotoma fuscipes) and shrews (e.g., Blarina brevicauda and Sorex cinereus) (Mather et al., 1989; Lane and Brown, 1991; Brown and Lane, 1992, 1996; LoGiudice et al., 2003; Lane et al., 2005; Brisson et al., 2008). Humans become infected when bitten by a tick that was previously infected while feeding on an infected host.

Clearly, for LD to occur, the reservoir hosts, tick vectors, and humans must all be in relative proximity to one another, but the factors that determine the spatial distributions of each of these organisms might be very different. For example, ticks might be much more strongly influenced by local temperature and humidity than are small mammals or humans (e.g., McEnroe, 1977, 1984; Belozerov, 1982; Knelle and Rudolph, 1982). Small mammals might be more strongly affected by the distribution of habitats providing abundant food, cover, and nesting sites, which do not influence ticks or humans. Humans, in turn, are likely influenced by socio-cultural factors and demographic trends rather than more traditional ecological factors. Lyme disease risk and incidence should be greatest where abundant populations of all of these taxa coincide, but our ability to predict these locations a priori is poor, as is our understanding of their root causes. Nevertheless, many studies of the spatial distributions of one or more necessary components of the North American LD system and some post hoc analyses of a suite of potential causes of that variation have been published in recent years.

In this article, we review the published literature on patterns and potential causes of spatial variation in components of the North American LD system to search for generalities. The identification of specific environmental factors that are consistently associated with elements of $\mathrm{LD}$ would facilitate both the management of LD where it currently exists and the prediction of future distributions as local, regional, or global environmental factors change. We focus on reviewing, respectively, the factors that have been proposed to influence human incidence rates (number of cases per capita per year) and tick densities, at all spatial scales that have been addressed. Tick densities are one ecological component of LD risk, the other ecological component being tick infection prevalence (proportion infected). There were insufficient numbers of studies to formally review the determinants of spatial variation in tick infection prevalence or densities of infected ticks, which is the product of tick densities and infection prevalence.

\section{HUMAN INCIDENCE}

Although LD cases have been reported throughout the entire United States, the vast majority occur in three regional hotspots-the Northeast, upper Midwest, and central to northern California (Orloski et al., 2000). Few if any rigorous analyses have addressed the large-scale question of why LD occurs predominantly in these three regions despite the much broader distribution of the tick vector and reservoir hosts (for exceptions, see Dennis et al., 1998; Ostfeld and Keesing, 2000). Within each of these three regions, however, several studies have addressed potential causes of spatial variation in LD incidence. Before reviewing these studies, some aspects of LD reporting relevant to spatial variation must be discussed.

The patterns in human incidence are determined using passive or active surveillance data gathered by county health departments. Passive surveillance, the primary method used, depends on heath-care providers reporting cases to governmental entities, typically county and state health departments, which vary in the probability that they will further assess these reports. This system can result in underreporting if providers are not diligent in notifying health departments, or in over-reporting if cases are misdiagnosed. 
For example, only $34 \%$ of actual LD cases in north-central Wisconsin were reported via passive surveillance (Naleway et al., 2002). Alternatively, some county and state health departments conduct active surveillance, where they contact health-care providers requesting incidence data. Active surveillance should result in more representative data, although systematic comparisons of the accuracy of these two methods in LD epidemiology have not been conducted.

Both types of surveillance data provide spatial information, which is typically in the form of the street address of the patient. However, analyses of these data for spatial patterns must confront the issue of what spatial scale(s) is most appropriate. Incidence data are typically aggregated at the county-level and occasionally at the zip code-level, which can be useful for large (e.g., national or regional) scale analysis when paired with environmental variables at a similar resolution. For local (e.g., county) analysis, it is necessary to use data with the complete address information. The geocoded incidence data can then be analyzed with high resolution demographic (e.g., census block populations) and environmental data (e.g., land use or soil).

A pervasive assumption in studies of spatial determinants of variation in LD incidence rates in the northeastern United States is that LD is contracted peridomestically. This assumption is supported by research that found LD patients in endemic areas often have infected ticks in their yards or surrounding forest fragments (Falco and Fish, 1988; Maupin et al., 1991; Connally et al., 2006). Testing this assumption rigorously is difficult and requires additional data about a patient's behavior and travel around the time of potential contact with the vector tick, which is rarely collected (Connally et al., 2006). Although peridomestic exposure might be the rule, the proportion of cases contracted away from home is unknown and potentially substantial. If, for instance, a resident visits a local park and is infected there, this would violate the assumption of peridomestic exposure, adding noise or even bias to analyses of spatial determinants of LD cases. Moreover, in areas of the United States with very sparse or nonexistent tick populations, locally reported cases almost certainly represent exposure during travel to endemic zones.

It is also possible that LD is not being diagnosed or reported equitably across the United States. LD cases are often unrecorded because of diagnostic difficulties (e.g. absence of erythema migrans, or poor detection of erythema migrans in patients with dark skin; Fix et al., 2000). Areas with a longer history of LD probably have greater awareness among health-care professionals and the public and so are more likely to recognize and document LD cases. The potential inequity of LD reporting adds additional noise to spatial analyses, particularly when the spatial extent of the research extends outside of areas with long histories of LD. With these caveats in mind, we reviewed six articles that used passive, and two that used active, surveillance to analyze environmental and human demographic/behavioral causes of spatial variation in $\mathrm{LD}$ incidence rates (Appendix 1).

Several studies, at multiple scales, have found that the presence and amount of forest on, or in close proximity to, individual properties is a good predictor of LD among members of a household (Glass et al., 1995; Kitron and Kazmierczak, 1997; Orloski et al., 1998; Eisen et al., 2006b; Jackson et al., 2006a). In Baltimore County, Maryland, there were more cases of $\mathrm{LD}$ associated with residences located in forested areas than non-forested areas (Glass et al., 1995). Similarly, the percentage of forest cover was found to be a significant predictor of LD incidence, using three different spatial resolutions $\left(10 \mathrm{~km}^{2}\right.$ grids, $36 \mathrm{~km}^{2}$ grids, and road bound polygons between $0.002 \mathrm{~km}^{2}$ and $368 \mathrm{~km}^{2}$ ), for a 12-county area in Maryland (Jackson et al., 2006ab). A larger scale analysis in Wisconsin found that counties with a higher average NDVI (a remotely sensed vegetation index), a surrogate for forest cover, had higher rates of LD (Kitron and Kazmierczak, 1997). The association between $\mathrm{LD}$ and the presence of forested areas is not surprising; it is strongly supported by research that has found that Ixodes tick densities are significantly higher, and thus risk is elevated, in wooded areas than in other land cover types, as described below.

This association might also be influenced by forest fragmentation, which is associated with residential development or other human alterations of the landscape. The simultaneous increase in suburban development and emergence of LD led to the hypothesis that forest fragmentation increases LD incidence. Two studies (Cromley et al., 1998; Brownstein et al., 2005), tested, but found no support for the hypothesis that increased fragmentation leads to increased LD incidence. Both studies focused on LD endemic areas in Connecticut and utilized the same human incidence and land cover data, but analyzed those data at different scales with different parameters of development.

Cromley et al. (1998) calculated incidence employing two methods that produced high resolution (village or census-block group) estimates, and concluded that human incidence is higher in low- than in medium-density resi- 
dential developments or villages for the 12 town area surrounding Lyme, Connecticut. Brownstein et al. (2005) expanded the analysis of forest fragmentation to the entire state of Connecticut and summarized incidence data at the town level. Despite these differences, the overall results were similar in that fewer cases of LD occurred in areas where forests were smaller and more isolated, i.e., in suburban developments. Likewise, highly developed residential areas had lower risk in Baltimore County, Maryland (Glass et al., 1995). The correlation between rural landscapes and higher incidence was also supported by a case-control study in Hunterdon County, New Jersey (Orloski et al., 1998).

Jackson et al. (2006a), however, found that neither development type nor population density were significant factors affecting LD incidence rates in Maryland. LD incidence rate was positively correlated with the number of small patches, but the relationship was too weak to include in the model (Jackson et al., 2006a). A primary methodological difference between Brownstein et al. (2005) and Jackson et al. (2006a) was the manner in which Jackson et al. (2006a) divided the study area. To avoid using ecologically or epidemiologically irrelevant spatial analysis units, the study area was divided into 514 road-bounded landscapes. The landscapes were delineated using major roads as boundaries, because some wildlife hosts of $B$. burgdorferi and the vector ticks are unlikely to move freely across such barriers.

Although the number of small fragments had a weak positive effect on LD incidence rate, the most significant factor was the percentage of land-cover edge consisting of adjacent forest and herbaceous land-cover (Jackson et al., 2006a). While edge environments do not have higher entomological risk than adjacent forests (Horobik et al., 2006), it is possible that edges are utilized more frequently or differently by humans, which may result in higher contact rates with infected ticks. Limited research has assessed how human behavior influences LD incidence (e.g., Carroll and Kramer, 2001; Lane et al., 2004) but, to our knowledge, how humans interact with edge habitats has not been tested. It also is possible that the importance of edge environments may be linked to the presence of many small forest fragments instead of fewer, larger ones. Studies have demonstrated that small fragments have higher entomological LD risk (Allan et al., 2003; Brownstein et al., 2005).

Despite the apparent necessity of forests for LD incidence to be high, not all forested areas in the US have associated LD cases. It is also unclear why some forests in endemic areas are associated with higher incidence rates than others. Part of the answer may be climate. Climate is often thought to drive large-scale patterns in $\mathrm{LD}$, principally because I. scapularis and I. pacificus are highly susceptible to desiccation (Rodgers et al., 2007). Thus, climatic factors that reduce relative humidity (e.g., low precipitation or high Palmer Hydrological Drought Index [PHDI]) may decrease tick abundance (Subak, 2003; McCabe and Bunnell, 2004; Schauber et al., 2005). Most research that has examined the effect of climate on LD in the United States has focused on temporal rather than spatial variability. These studies use spatial datasets but each of the geographic components (e.g., counties, states, etc.) is analyzed as individual points in time (Subak, 2003; McCabe and Bunnell, 2004; Schauber et al., 2005). One study assessing the importance of climate and abundance of hosts for ticks in affecting LD incidence rates found that small-mammal abundance generally had a stronger impact than did climatic variables (Schauber et al., 2005). The only explicitly spatial analysis of LD and climate was conducted in California (Eisen et al., 2006b).

In California, higher resolution incidence and climate data, summarized by zip code rather than county, highlighted several isolated areas of elevated LD incidence that were not apparent during analysis of county-level data (Eisen et al., 2006b). Additionally, the zip codes with higher incidence occurred in close proximity to forested areas with growing degree days between 2600 and 3000, which is a good predictor of entomological risk based on a model developed for northern California (Eisen et al., 2006b). The linking of a spatial entomological risk model and high resolution incidence data is an exciting development in LD research that needs to be further validated by further ground-truthing acarological follow-up studies.

\section{Density Of Ticks}

Understanding the abiotic and biotic factors that control tick density in any given area is crucial for the understanding and management of LD risk and incidence. In this section, we review studies that have explored causes of spatial variation in tick density, treating the two vector species in the United States, I. scapularis and I. pacificus, separately. These two vectors occur in different climatic zones and interact with different host species (Dennis et al., 1998).

I. scapularis occurs throughout the eastern and central United States. The adult ticks feed and reproduce on white- 
tailed deer (Odocoileus virginianus) and other large and medium-sized mammals during the autumn or early spring. In the spring, the female ticks produce egg masses that hatch later that summer into larvae, which are virtually free of B. burgdorferi. The larvae and nymphs are host generalists, and feed on a variety of lizards, birds, and mammals (Lane et al., 1991). Larvae can acquire B. burgdorferi if they feed on an infected, reservoir-competent host; the most competent reservoirs are white-footed mice (Peromyscus leucopus) and eastern chipmunks (Tamias striatus) (LoGiudice et al., 2003). Fed larvae drop off their hosts, molt into potentially infected nymphs, overwinter, and then seek a mammalian or avian host the following late spring or early summer. Strong mid-summer peaks in LD incidence (CDC, 2007) strongly implicate nymphs as the life stage responsible for the vast majority of transmission events to humans. After feeding, nymphs molt into adults and emerge later in the year to quest for a host, thus completing the life cycle.

I. pacificus occurs in California and other parts of the western United States. Adult I. pacificus ticks generally quest and feed on large mammals (e.g., Columbian blacktailed deer) in late fall, winter, and early spring. Female ticks oviposit in late winter or early spring (Westrom et al., 1985). Eggs hatch mid- to late summer, but the uninfected larvae remain inactive until the late winter or early spring (Padgett and Lane, 2001). The peak activity of larvae and nymphs occurs simultaneously during the early spring, and they both feed on a variety of hosts, including lizards, birds, and small mammals. The primary reservoir hosts for B. burgdorferi are dusky-footed woodrats (Neotoma fuscipes), California kangaroo rats (Dipodomys californicus), deer mice (Peromyscus maniculatus), and western gray squirrels (Sciurus griseus) (Lane and Brown, 1991; Brown and Lane, 1992, 1996; Peavey and Lane, 1995; Lane et al., 1999, 2005). The western fence lizard (Sceloporus occidentalis) is an important host of subadult I. pacificus, but this species is reservoirincompetent (Lane and Loye, 1989; Lane, 1990; Lane and Quistad, 1998; Eisen et al., 2001). The diversion of subadult blood meals to certain species of lizards contributes to lower enzootic transmission of B. burgdorferi in the western than in the northeastern US (Lane and Quistad, 1998; Wright et al., 1998).

The density of ticks is one of the key local risk factors for LD. Since the primary means of preventing LD is human avoidance of B. burgdorferi-infected ticks, it is essential to understand the environmental factors that promote or limit tick density. Next, we review several studies that have examined how the density of ticks varies in space in relation to environmental factors.

\section{DENSITY OF IXODES SCAPULARIS}

In the northeastern and midwestern United States, wooded areas or forests repeatedly have been shown to support higher tick populations than nearby lawns or other more open habitats (Kitron et al., 1991; Maupin, 1991; Stafford and Magnarelli, 1993; Duffy et al., 1994; Ostfeld et al., 1995; Frank et al., 1998; Guerra et al., 2002; Appendix 2). The relationship between forest cover and tick density has been found for all three parasitic life stages and at multiple spatial scales, including those used in remote-sensing studies (Dister et al., 1997; EstradaPeña, 2002; Rodgers and Mather, 2006; Appendix 3). Tick abundance is generally higher in fragmented deciduous moist forest with shrub-dominated understories than in coniferous forests, wetlands, old fields, urban environments, or large continuous forests (Glass et al., 1994; Guerra et al., 2002; Allan et al., 2003; Lubelczyk et al., 2004; Brownstein et al., 2005).

Despite the prevailing assumption that higher tick densities in forests arise because of milder, moister conditions found therein (Lubelczyk, 2004), the mechanisms underlying this relationship have been inadequately studied. We were unable to find published studies supporting the hypothesis that spatial variation in tick densities either within or among specified habitat types is caused by spatial variation in temperature or humidity. However, a few studies have examined the large-scale patterns of I. scapularis across the eastern United States in relation to climatic correlates (Appendix 4). One study measured nymphal and adult tick densities, temperature, relative humidity, and atmospheric pressure at 95 locations across the eastern U.S.; it found that mean temperature and saturation deficit were negatively correlated with tick density while latitude was positively correlated with tick density (Duik-Wasser et al., 2006). In another study, tick presence/absence data derived from Dennis et al. (1998), and 16 monthly climatic variables (i.e., mean, maximum, minimum, and standard deviation of maximum temperature, minimum temperature, mean temperature, and vapor pressure) were used to derive a complex statistical model (Brownstein et al., 2003). The simplest relationship between any individual climatic variable and tick abundance in this study was a fourth- 
order polynomial. The final model included eight variables: four terms related to the maximum of the mean temperature and one each related to the maximum of the minimum temperature, the mean minimum temperature, the minimum mean temperature, and the standard deviation of the vapor pressure. Unfortunately, such complex statistical relationships are difficult to interpret, and the authors provided no biological support for the selected climatic variables. Moreover, models predicting future tick distributions based on current correlations between tick distribution and climatic variables must assume that tick distributions are: (1) limited by climatic conditions versus being limited by habitat, host availability, or natural enemies; and (2) in equilibrium, i.e., ticks occur everywhere climatic conditions are permissive. Neither assumption has been validated so far. The spatial distribution of ticks also is potentially influenced by soil type (Appendix 5). Two small-scale studies found that tick burdens on hunter-killed deer were positively associated with sandy soils (Kitron et al., 1991; Glass et al., 1994). Two larger scale regional analyses also found that questing tick densities were higher on sandy or sandy loam soils than on other soil types (Guerra et al., 2002; Bunnell et al., 2003). The influence of soil type is difficult to interpret because soils are generally not independent of vegetation type nor of many other sitespecific factors.

Another potential cause for local spatial variation of tick densities between forested sites is the presence/absence or density of certain hosts (Appendix 6). Correlations between spatial variation in tick density and that of white-tailed deer have been actively pursued and sometimes found. Deer density was used successfully to predict larval tick densities on 13 islands off the coast of Massachusetts (Wilson et al., 1985; Anderson et al., 1987). When deer were eliminated from these islands by hunting, tick densities plummeted (Wilson et al., 1988). Densities of adult ticks were positively correlated with those of deer pellet groups, a metric of deer density, at eight sites in southern Maine over 3 years (Rand et al., 2003). In other cases, however, spatial associations between deer and ticks have been weak (Schulze et al., 2001; Jordan and Schulze, 2005), nonexistent (Ostfeld et al., 2006), or even negative (Perkins et al., 2006). Other host species may also be important, especially in influencing abundance of nymphal ticks, which transmit most B. burgdorferi infections to people. An analysis of six forest plots in southeastern New York State over 12 years supported positive correlations between plot-specific densities of nymphal ticks and prior densities of white-footed mice and eastern chipmunks (Ostfeld et al., 2006).

\section{DeNSITY Of IXODES PACIFICUS}

Several papers have examined the spatial variation of $I$. pacificus in northern California (Appendix 7). This research has focused on forests or woodland sites, primarily in Mendocino County, and has examined the local (county level) influences of habitat, topography, deer density, and climate on tick densities. This literature provides mixed support for three habitat variables—-brush, logs, and forest type-affecting tick densities. Percent brush density was positively correlated with the density of adult ticks in one study (Li et al., 2000), but was not included in any other studies that examined habitat variables because most studies focused on dense-woodland habitats. Number of logs was significantly correlated with nymphal tick abundance in one study (Tälleklint-Eisen and Lane, 2000), although other studies found that logs were not a significant predictor of tick density (Eisen et al., 2003, 2006a). Similarly, hardwood-dominated habitats had higher tick densities than redwood or pine habitats in one study (Eisen et al., 2006a). The significance of several other variables (i.e., leaf litter depth, number of branches, tree-to-stump ratio, and tree species) varied from year to year (TälleklintEisen and Lane, 2000). The inter-annual variability found in these studies highlights the complex interactions that occur in the LD system, especially in ecologically diverse regions like Mendocino County. There are several potential interactions between habitat, hosts, and climate that vary from year to year, making it difficult to establish consistent relationships between environmental variables and tick densities. For example, in a very dry year, leaf litter depth may be important for tick survival because it provides protection from desiccation, whereas in a wet year, it may be unimportant.

As with I. scapularis, blood meal hosts are important to I. pacificus. The Columbian black-tailed deer, Odocoileus hemionus columbianus, is the primary reproductive host of I. pacificus (Westrom et al., 1985). Presence of deer trails and bedding areas was positively associated with nymphal tick density (Eisen et al., 2006a). The relationship between deer signs and tick density varied annually in another study (Tälleklint-Eisen and Lane, 2000). The nests of the duskyfooted woodrat were not significantly related to tick density (Eisen et al., 2006a). 
In addition to habitat and hosts, climate may also influence the spatial distributions of ticks in California. At the county scale, spatial trends in climate are generally not significant in statistical models that include other habitat variables (Eisen et al., 2003). However, forested areas having annual growing degree days ranging between 2600 and 3000 were found to have elevated densities of nymphs compared to similar areas with fewer or more growing degree days (Eisen et al., 2006b). This suggests that there may be some climatic constraints to I. pacificus populations.

Topographic variables have often been included in models of tick density in California (Appendix 8). Slope, aspect, and elevation influence microclimate and habitat type. However, the research has repeatedly shown that topographic variables are not significant predictors of nymphal tick density. Adult tick density, however, was found to be positively correlated with presence of an uphill slope (Li et al., 2000). One study found that sites with a lower water infiltration rate (i.e., poorer drainage) had larger tick populations (Eisen et al., 2006a), a result that contrasts with results for I. scapularis described above. Information about the spatial distribution of I. pacificus and ecological determinants of the distribution beyond northern California has been unexplored.

\section{IXODES RICINUS AND TICK-BORNE DISEASES IN EUROPE}

A series of studies have addressed spatial dynamics of Ixodes ricinus in Europe, a phylogenetically and ecologically related species. Although a comprehensive review of this literature is beyond the scope of this article, some comparisons are useful. Compared to North American LD studies, European studies tend to focus more on climate and less on local site-specific or landscape characteristics affecting the geographic distribution of $I$. ricinus. The emergence of LD in new localities has often been associated with climate warming that results in latitudinal and altitudinal expansion of the tick's geographic range (Lindgren et al., 2000; Daniel et al., 2003). Later onset of cold weather in autumn and less extreme winter cold are changes postulated to allow tick populations to expand into previously unoccupied areas (Lindgren and Jaenson, 2006). Specifically, in the Czech Republic during the early 1980s, I. ricinus was not found at elevations $>700 \mathrm{~m}$ asl, while more recent surveys have found population at elevations up to
$1100 \mathrm{~m}$ asl (Daniel et al., 2003). Similarly, in Switzerland, tick densities were found to decrease with elevation, suggesting an altitudinal limit to tick survival corresponding with decreasing temperatures (Jouda et al., 2004). Similarly, in Sweden, the distribution of ticks has moved northward (Lindgren et al., 2000). North American studies of the effects of climate change on distribution of I. scapularis focus largely on northward movement of the ticks due to sufficiently warm summer temperatures (e.g., Ogden et al., 2005, 2006) or changes in precipitation (Subak, 2003; McCabe and Bunnell, 2004) which is in contrast to the European focus on autumn or winter cold.

The effects of habitat type, fragmentation, and hosts on tick distribution and LD incidence in Europe may be important but there has been limited research on these topics (Randolph, 2001). A few studies have seen a positive effect of increasing deer population on tick abundance (Gray et al., 1992; Jensen et al., 2000). Others have found relationships between habitat type, particularly forests, and tick densities or disease prevalence (Estrada-Peña, 2001; Racz et al., 2006). The results of the European research on hosts and habitat, thus far, suggests that the European LD system responds to human influences similarly to the LD system in the northeastern United States.

\section{SUMmARY AND CONCLUSIONS}

The most robust conclusion arising from the published literature on the spatial dimensions of entomological risk of LD and measured LD incidence in North America is that forests comprise elevated risk compared to other habitat types. However, this conclusion does not require spatially sophisticated analyses; knowledge that ticks and reservoir hosts are more abundant in forests pre-dated this research focus. Unfortunately, no clear patterns at any spatial scale appear to explain why certain forests have more associated ticks or cases of LD than do others. Several abiotic and biotic factors have been used to explain the spatial variation in tick densities, LD incidence, or rate at various scales (e.g., climate at a regional scale, or soil or microclimate locally). Nevertheless, the relationships between LD risk or incidence and the potential abiotic and biotic explanatory variables are not well understood, with little or no concordance among studies. In some cases, the inconsistency could be caused by geographic variation in the explanatory variables, for instance, tick populations in an area dominated by sandy soils may require frequent precipitation. In 
this case, correlative studies would find a relationship between precipitation and tick density. However, an area with organic soils, which retain moisture, may not be as dependent on precipitation, and a positive correlation would not be expected. In other cases, the relationships between ticks and environmental variables might be inconsistent from year to year. The worst-case scenario is that stochastic factors are so important in determining spatial variation in tick abundance and infection prevalence that deterministic biotic or abiotic factors will not be detectable. This seems unlikely, however, given the known influence of host availability and climatic factors on ticks, and the known influence of spatially variable conditions on hosts and climate.

We suspect that the discordance among studies is due, at least in part, to the rapid developments in both conceptual and technological aspects of spatial ecology that hasten the obsolescence of earlier approaches. Some of the earlier limitations that are beginning to be overcome include the use of arbitrary (often political) boundaries to delineate spatial units that do not coincide with biological boundaries, the conflation of factors affecting ecological risk with those affecting human behavioral components of risk, and inconsistent or inadequate methods of tracking human cases (e.g., as case numbers rather than incidence or incidence rates).

The large suite of data on LD ecology amassed over the past 30 years makes this disease a model for other vectorborne zoonoses. Spatial variables that potentially affect vectors, hosts, and vector-host-pathogen interactions can be categorized into local-scale (e.g., soil type, vegetation type, local host community), meso-scale (e.g., landscape composition and configuration, regional host community), and large-scale (macroclimate, biogeography) effects. A key lesson from the LD literature is the importance of assessing multi-scale impacts on zoonotic risk or incidence incorporating explicit, mechanistic models of cause and effect.
As ever more detailed and sophisticated remotely sensed data and analytical methods become available for assessing spatial correlates of disease risk and incidence, it will become increasingly important to root explorations in biologically meaningful hypotheses. Future studies of LD and other zoonoses will need to better incorporate perspectives and techniques from many disciplines, including entomology, vertebrate ecology, bacteriology/virology/protozoology, geography, climatology, landscape ecology, and epidemiology. Effects of local-, meso-, and large-scale factors on human behaviors that influence contact rates with infected vectors are probably least well understood, but undoubtedly crucial in epidemiological patterns.

Detection of abiotic and biotic determinants of spatial variation in LD risk and incidence, as well as those of other zoonoses, would be facilitated by: (1) testing models in which the suite of potentially causal factors is determined a priori on the basis of the rich knowledge base regarding vector and host biology, rather than determined by expediency or post-hoc reasoning; (2) long-term and spatially distributed datasets that provide wide coverage of variable biotic and abiotic conditions; (3) consistent methods of data collection and analysis among regions; and (4) testing the effect of the same environmental variables at multiple spatial scales. Understanding the causes of spatial variation in LD risk is essential for the management and prevention of the disease. A coordinated approach to LD research is likely to provide health care professionals and environmental managers with information useful for reducing the burden of this and other tick-borne diseases on our society.

\section{ACKNOWLEDGMENTS}

This material is based upon work supported by the National Science Foundation under Grant No. EF-0525674. 


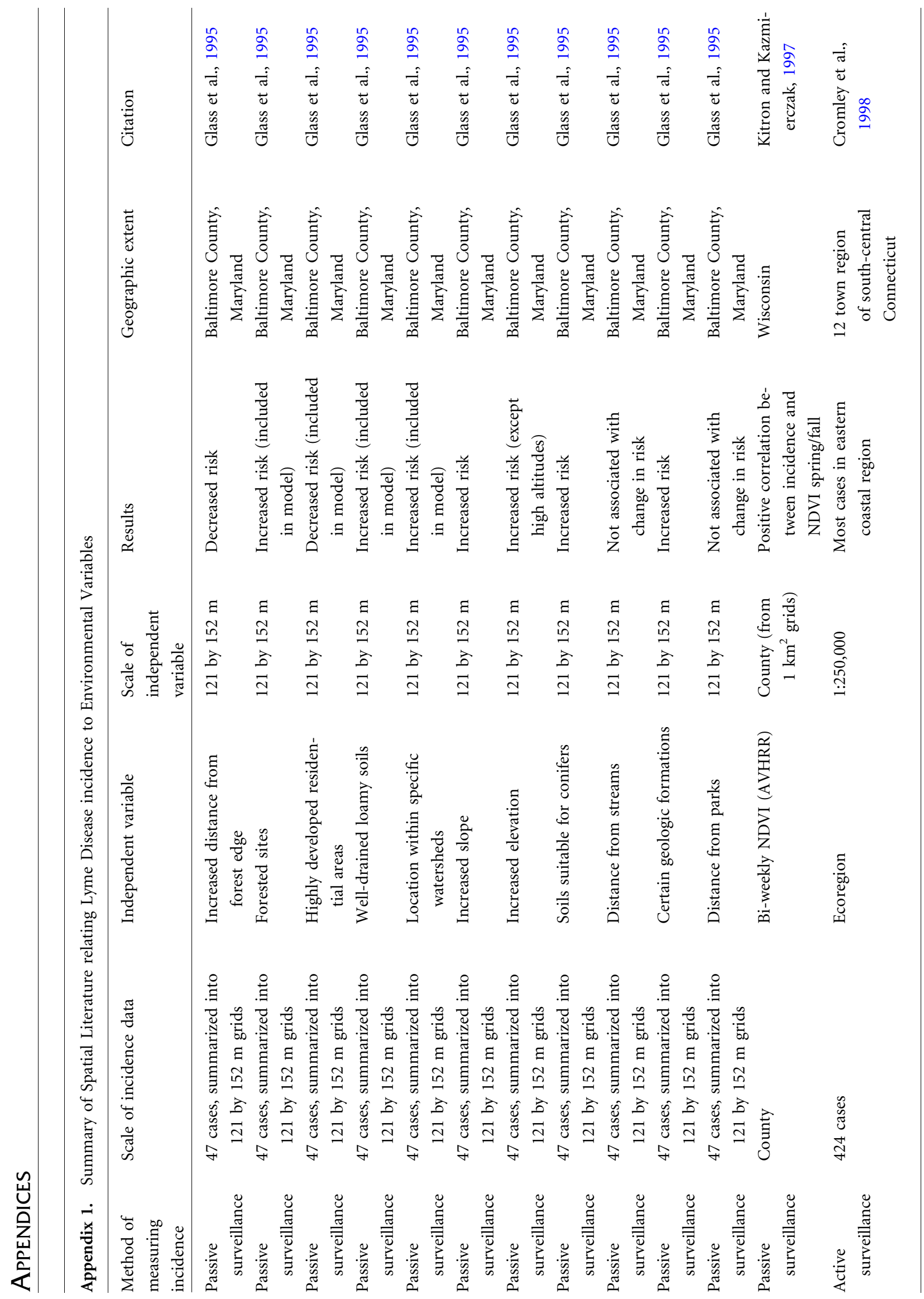




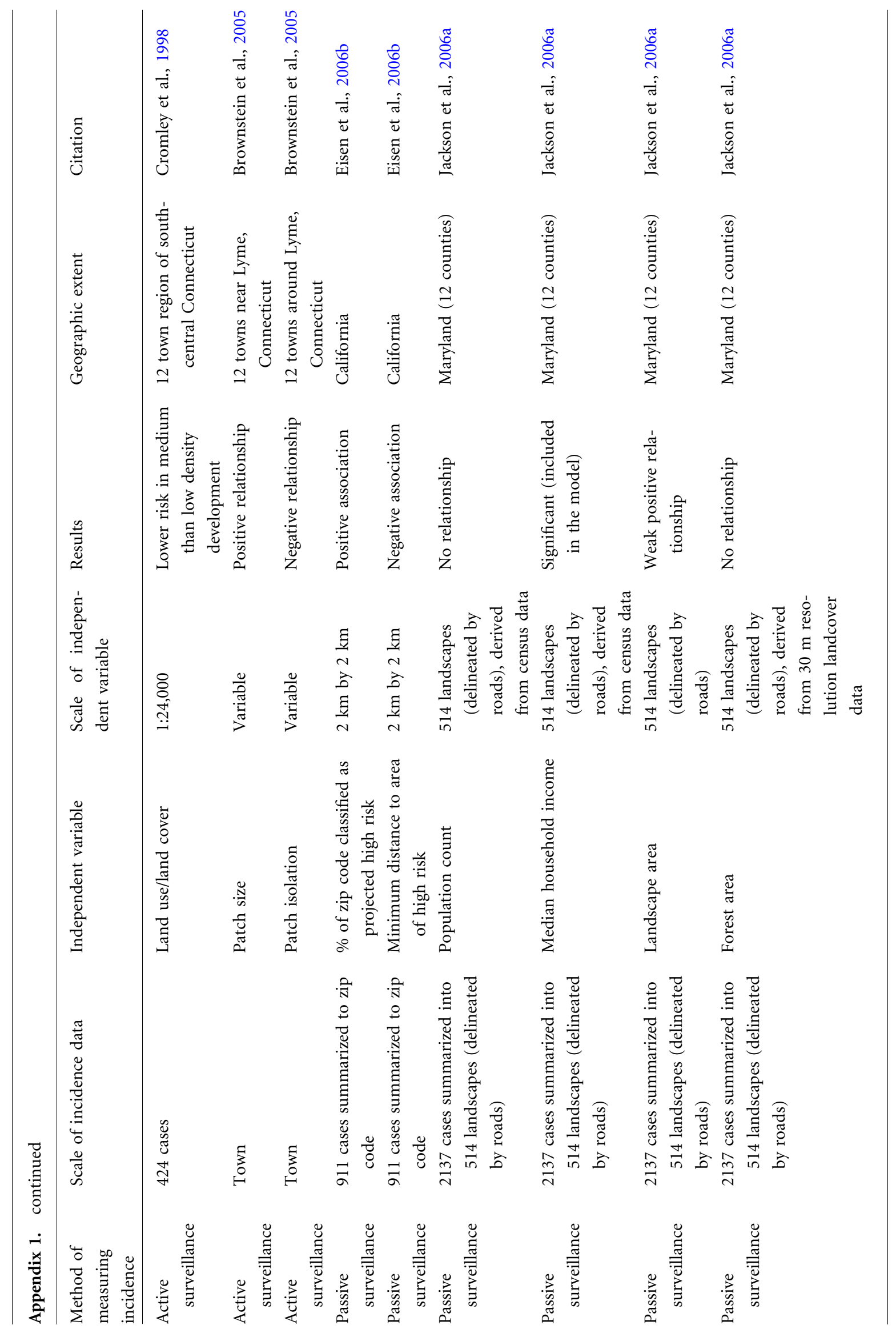




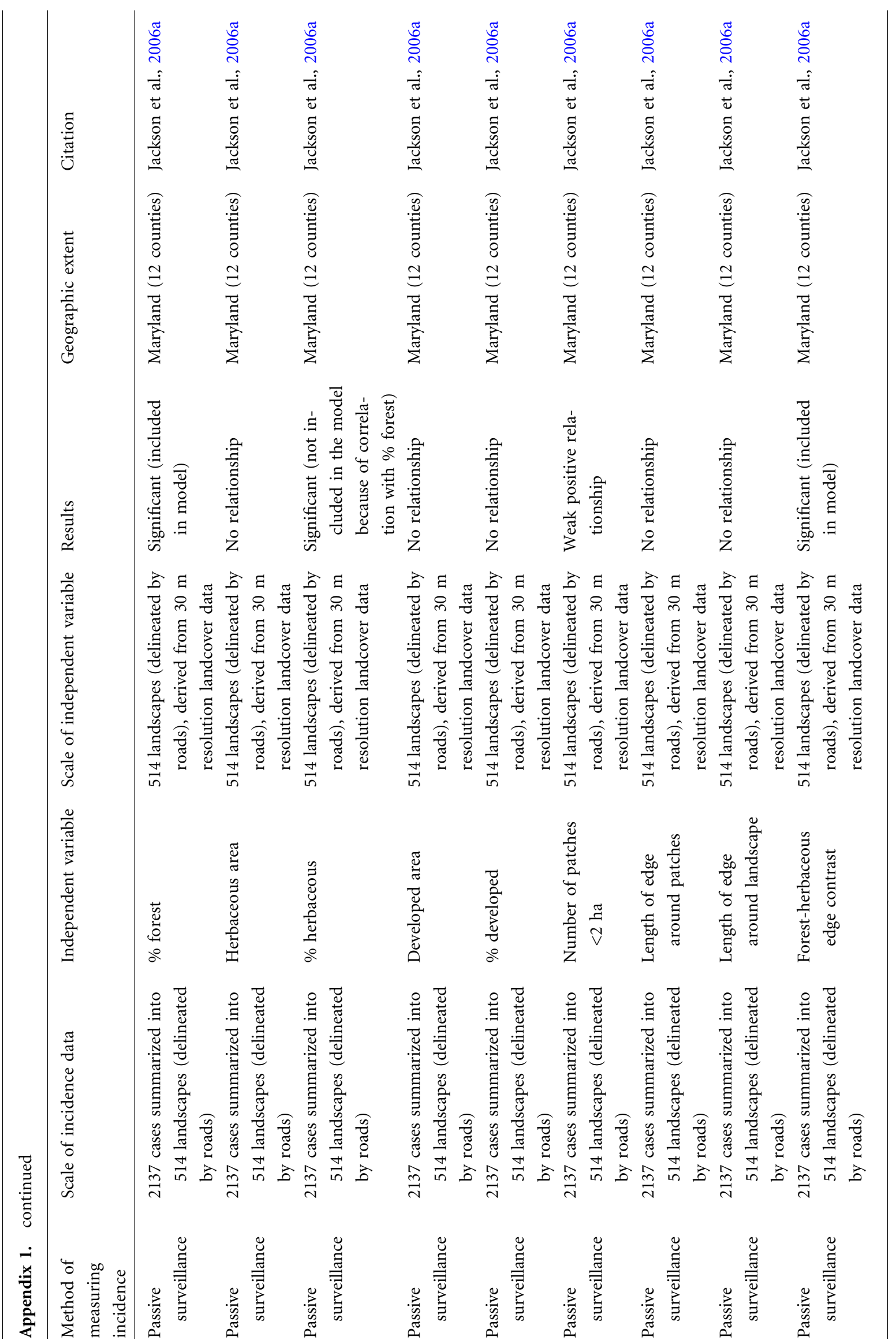


Mary E. Killilea et al.

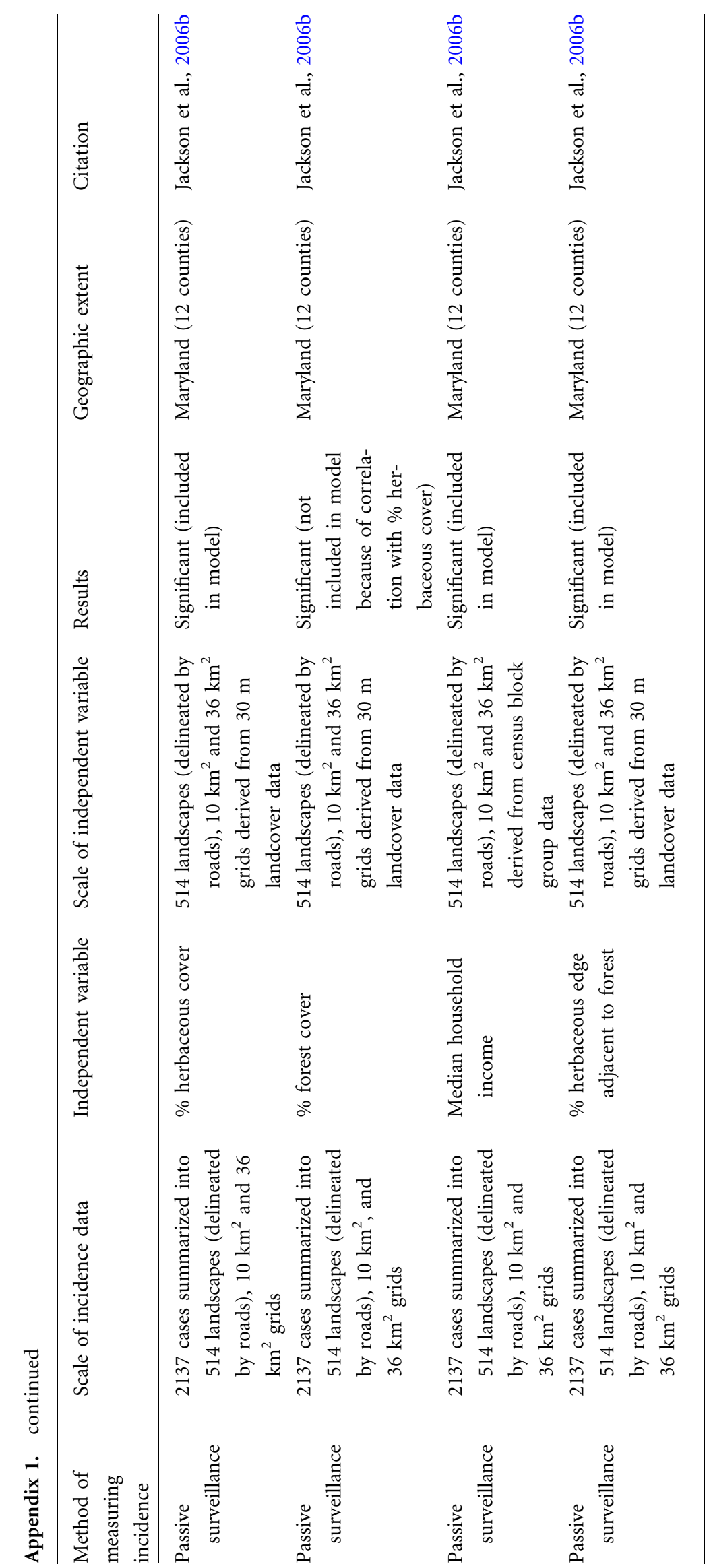




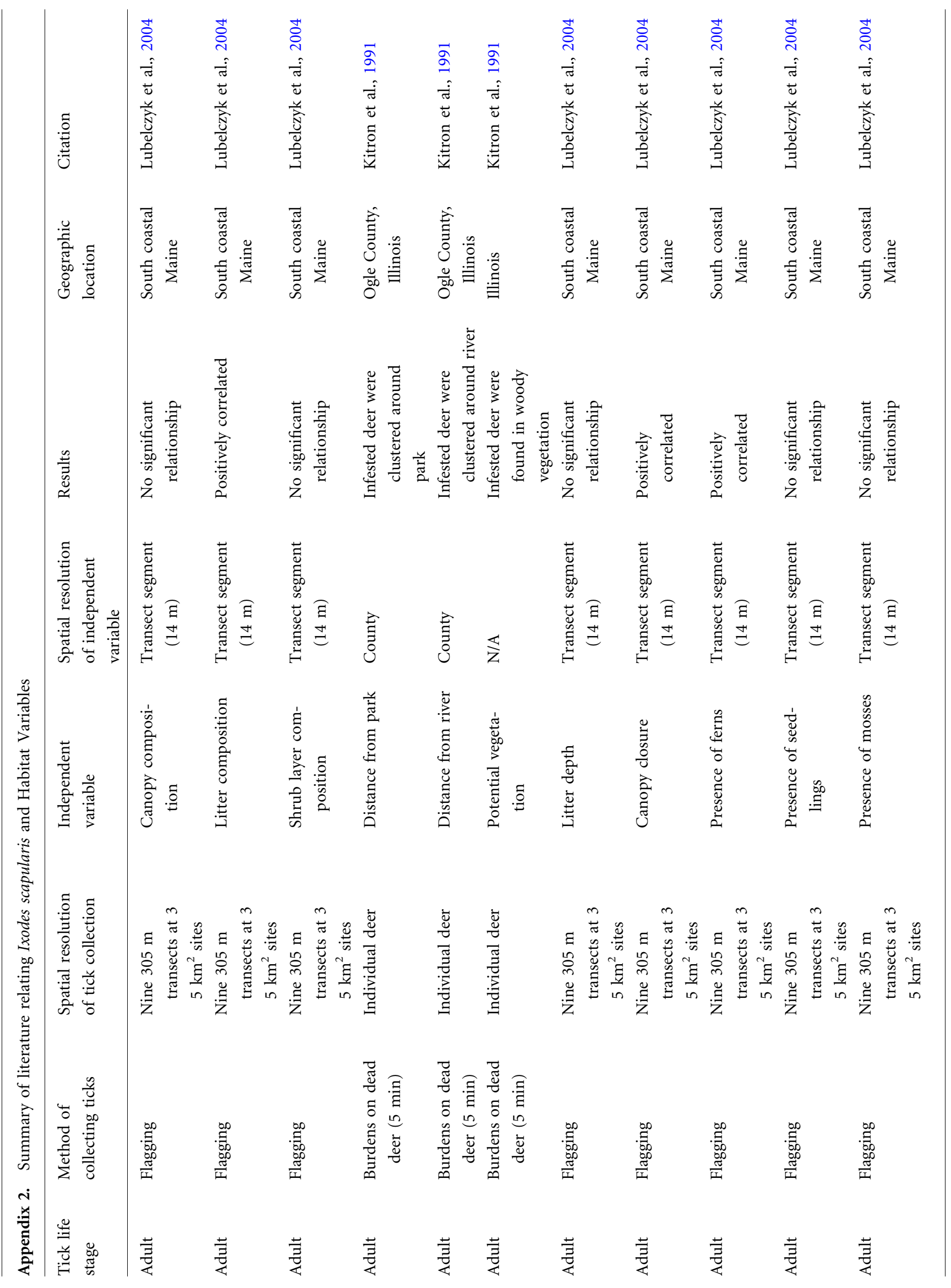




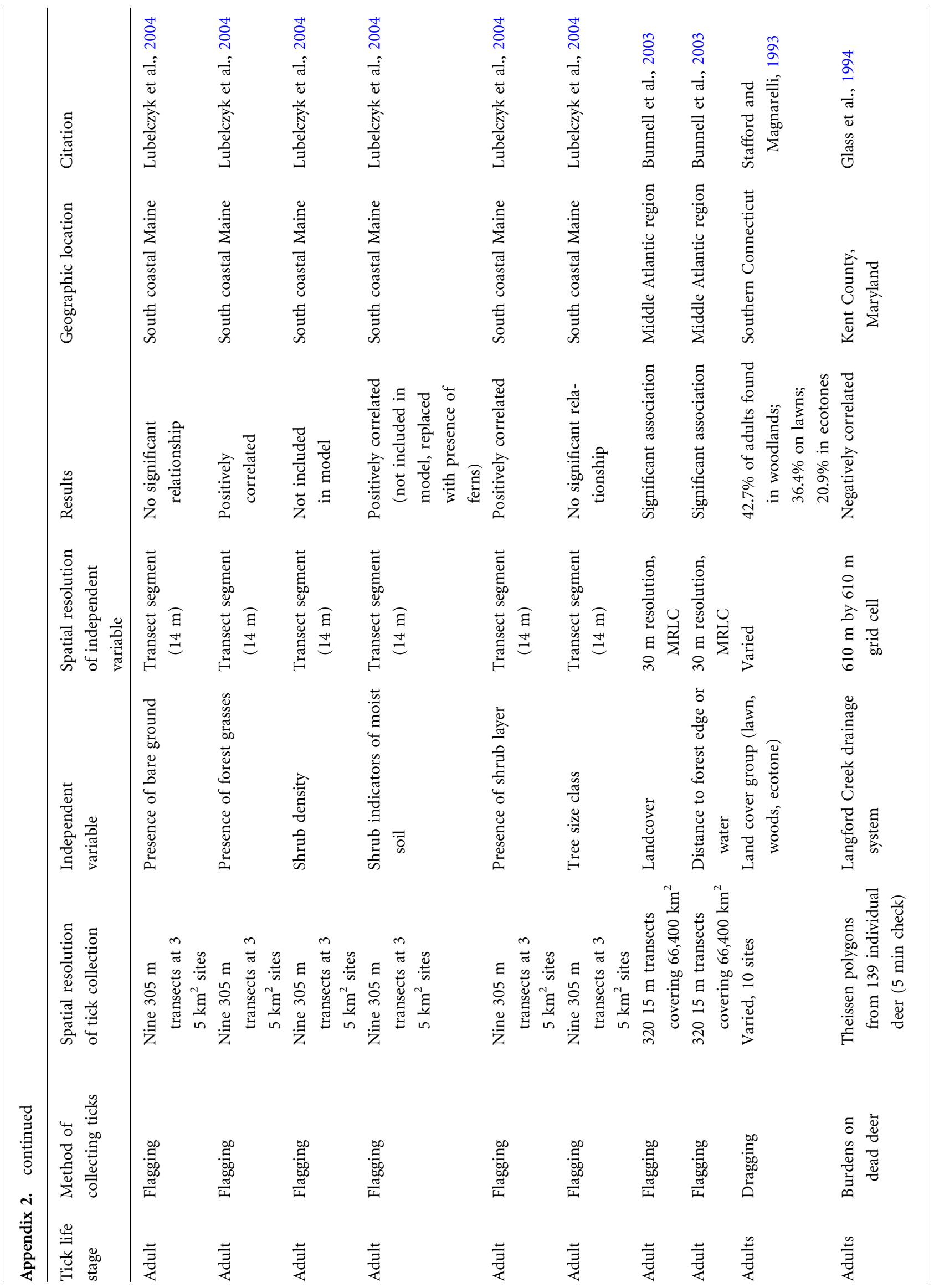




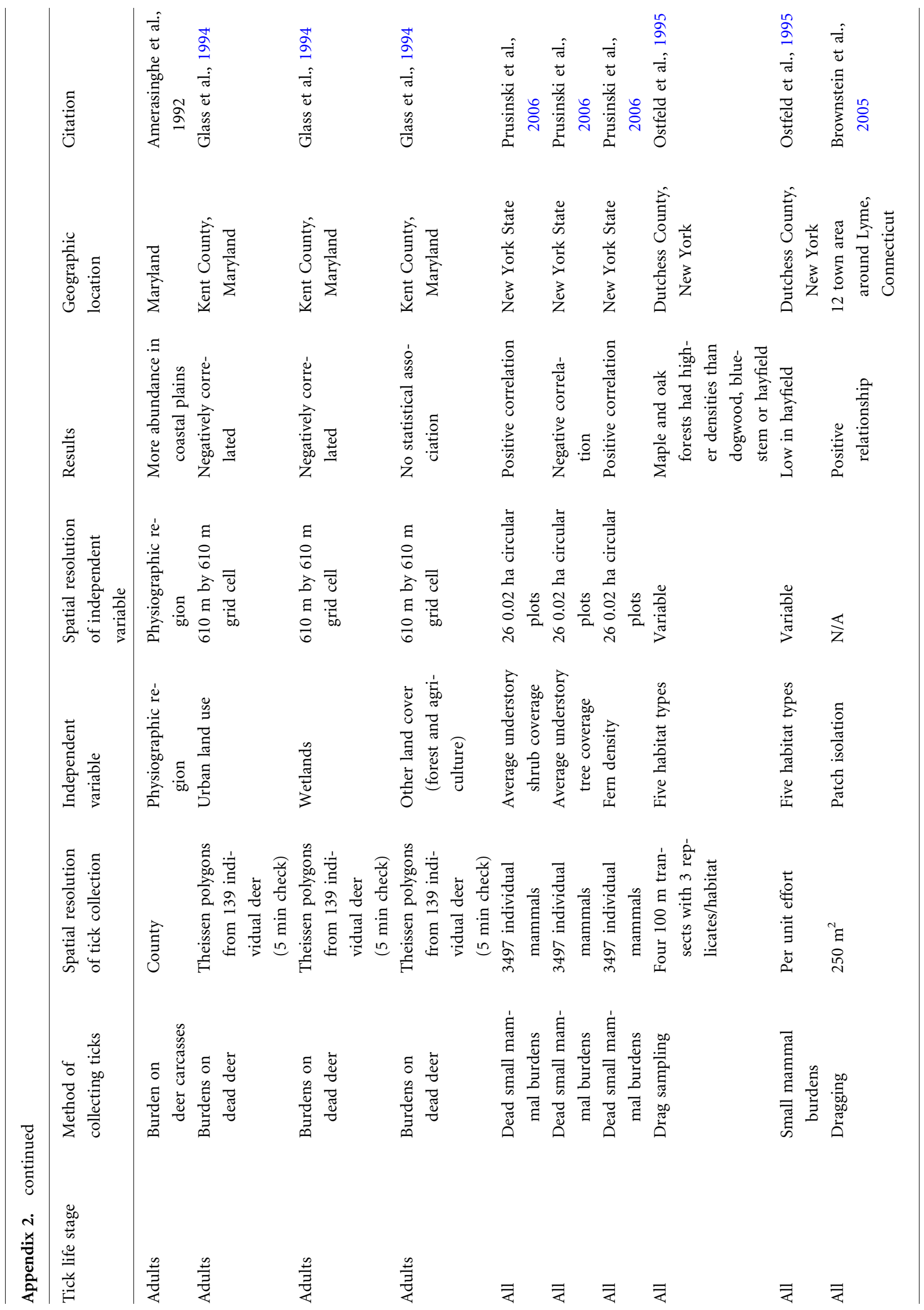




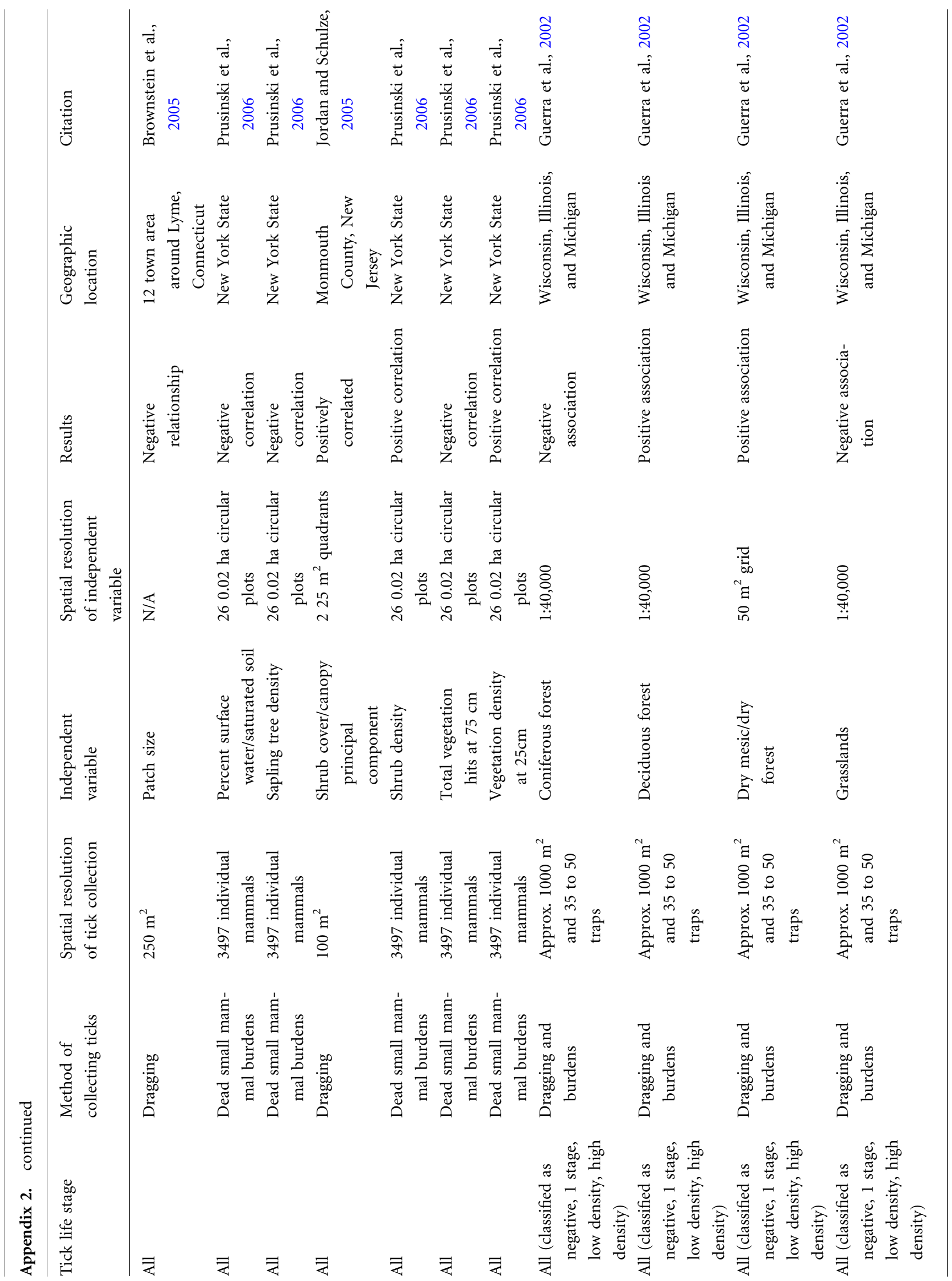




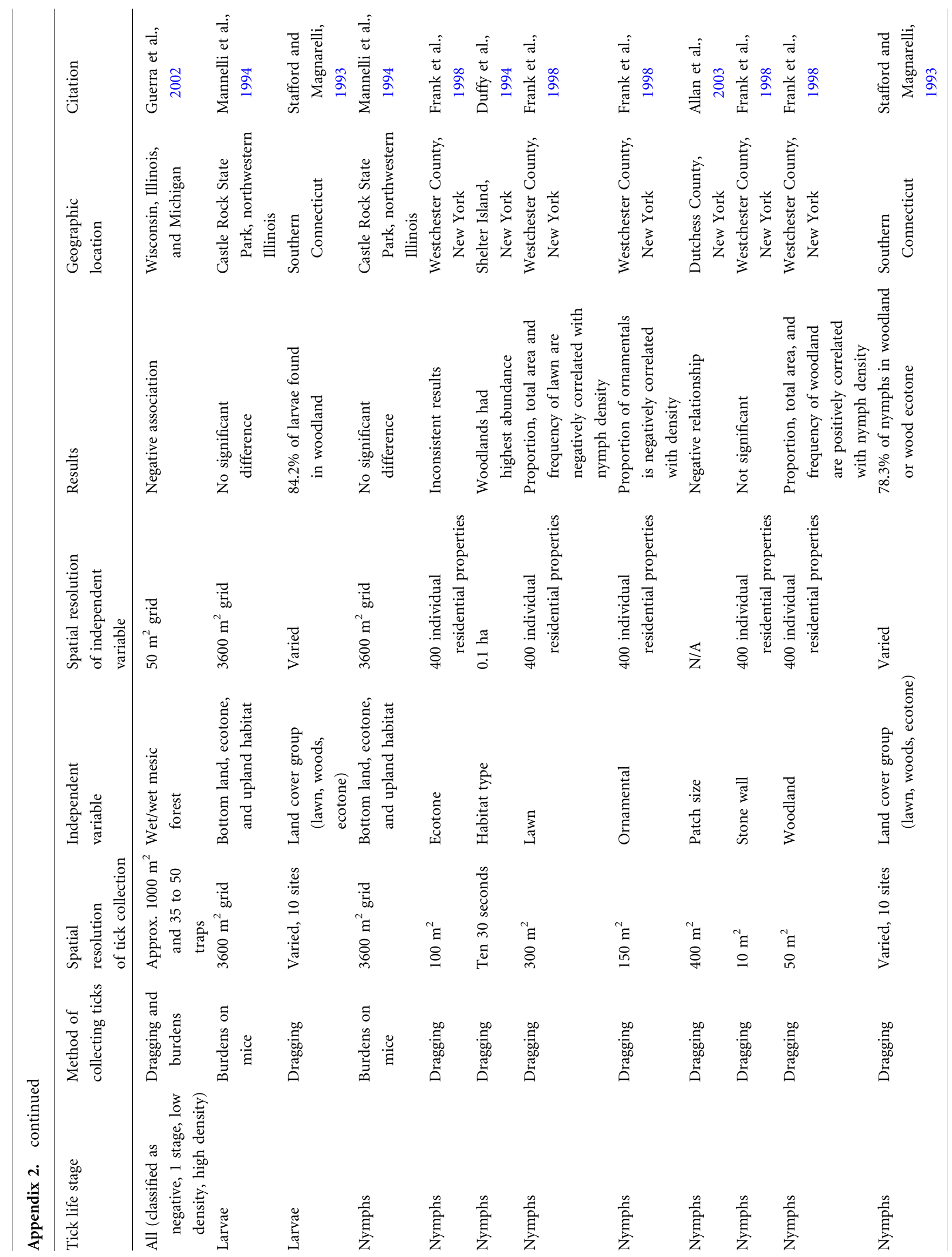




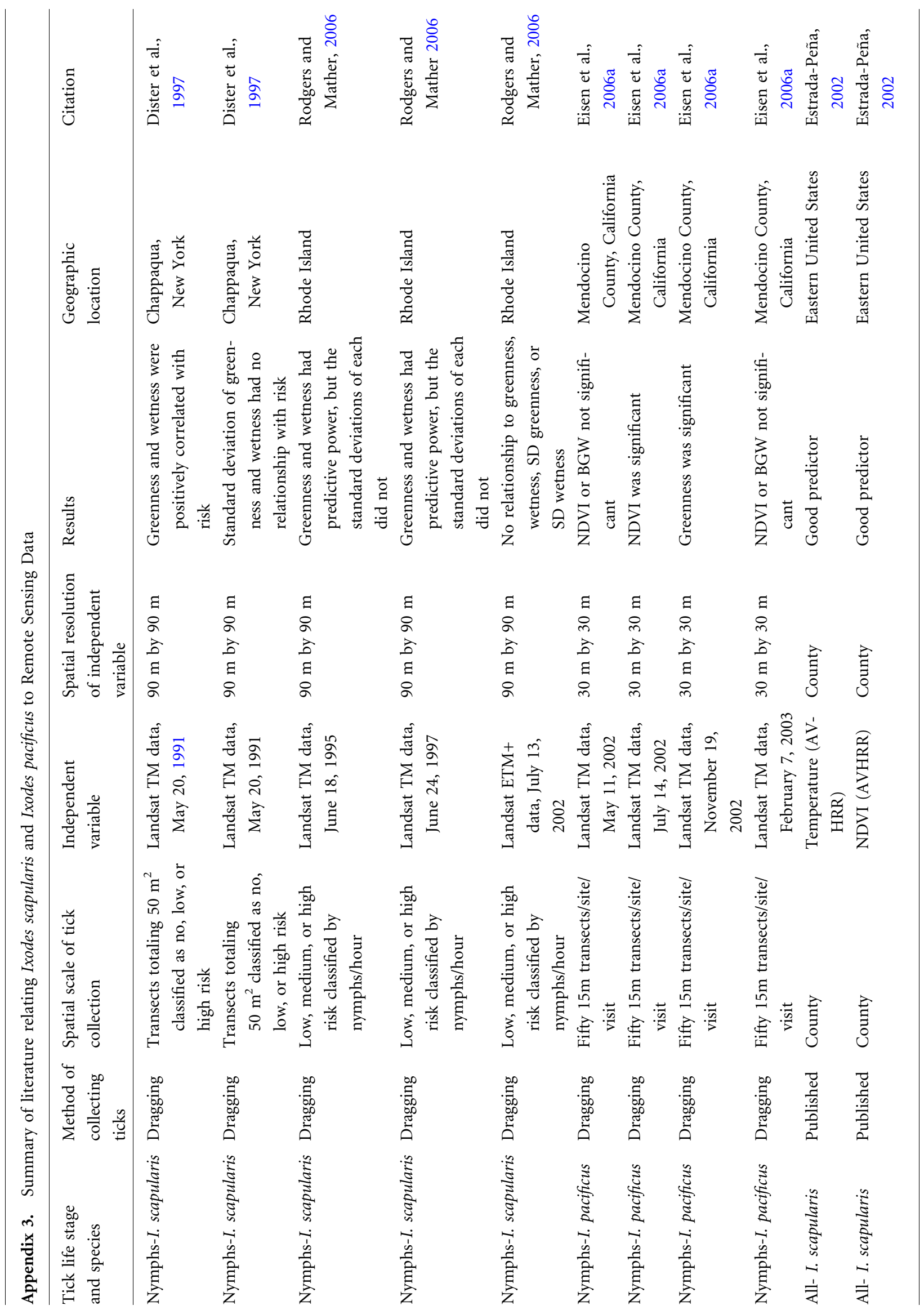




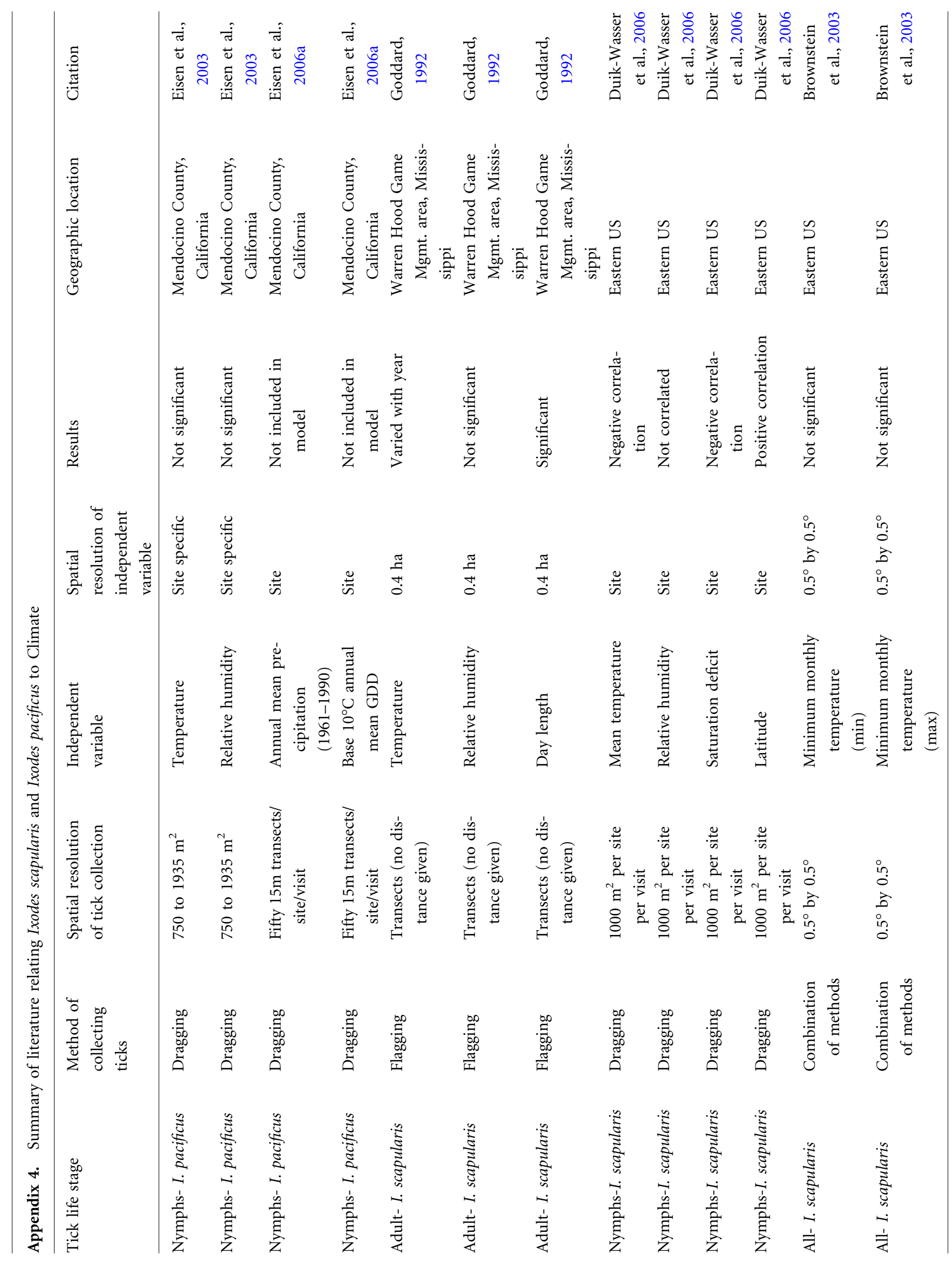




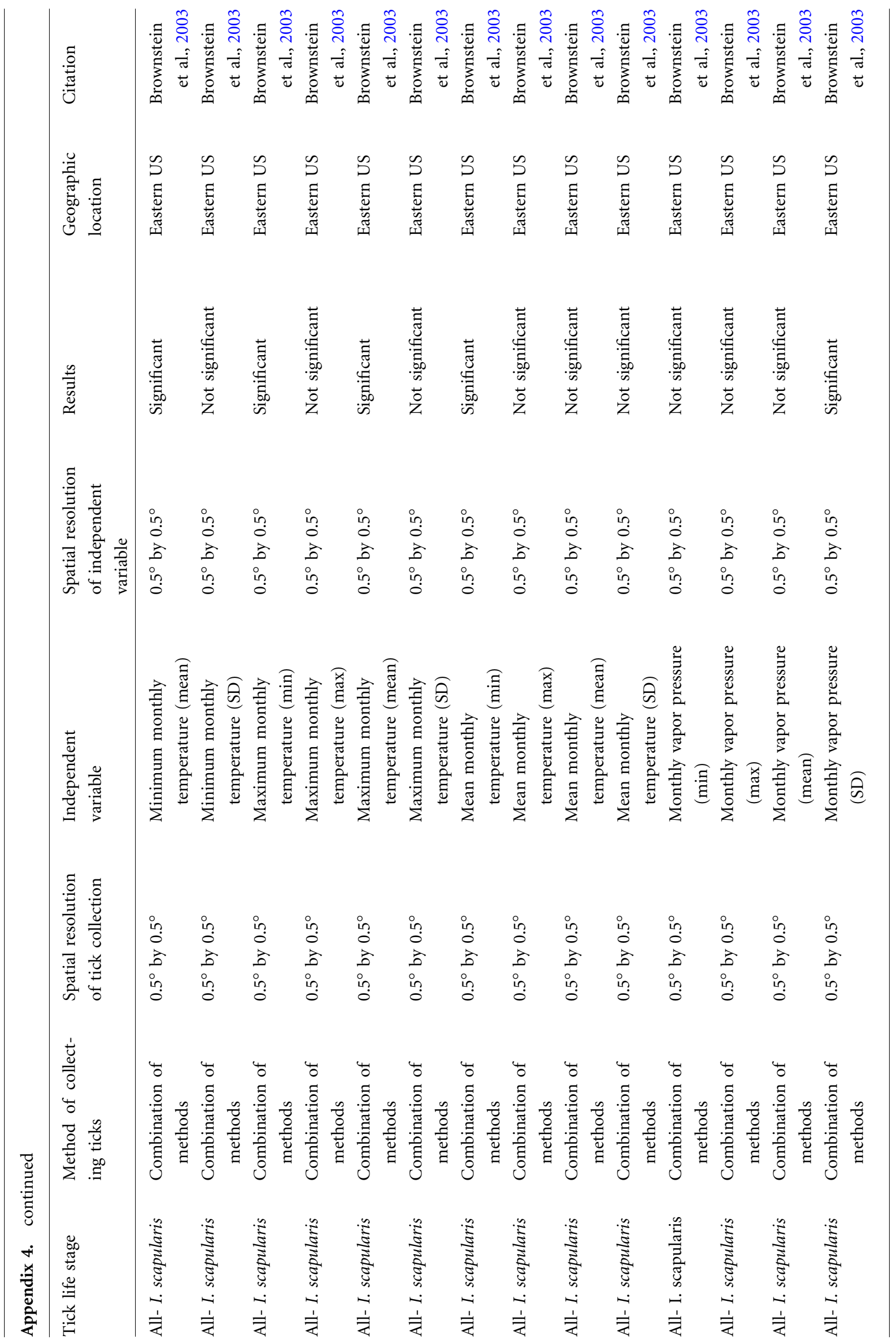



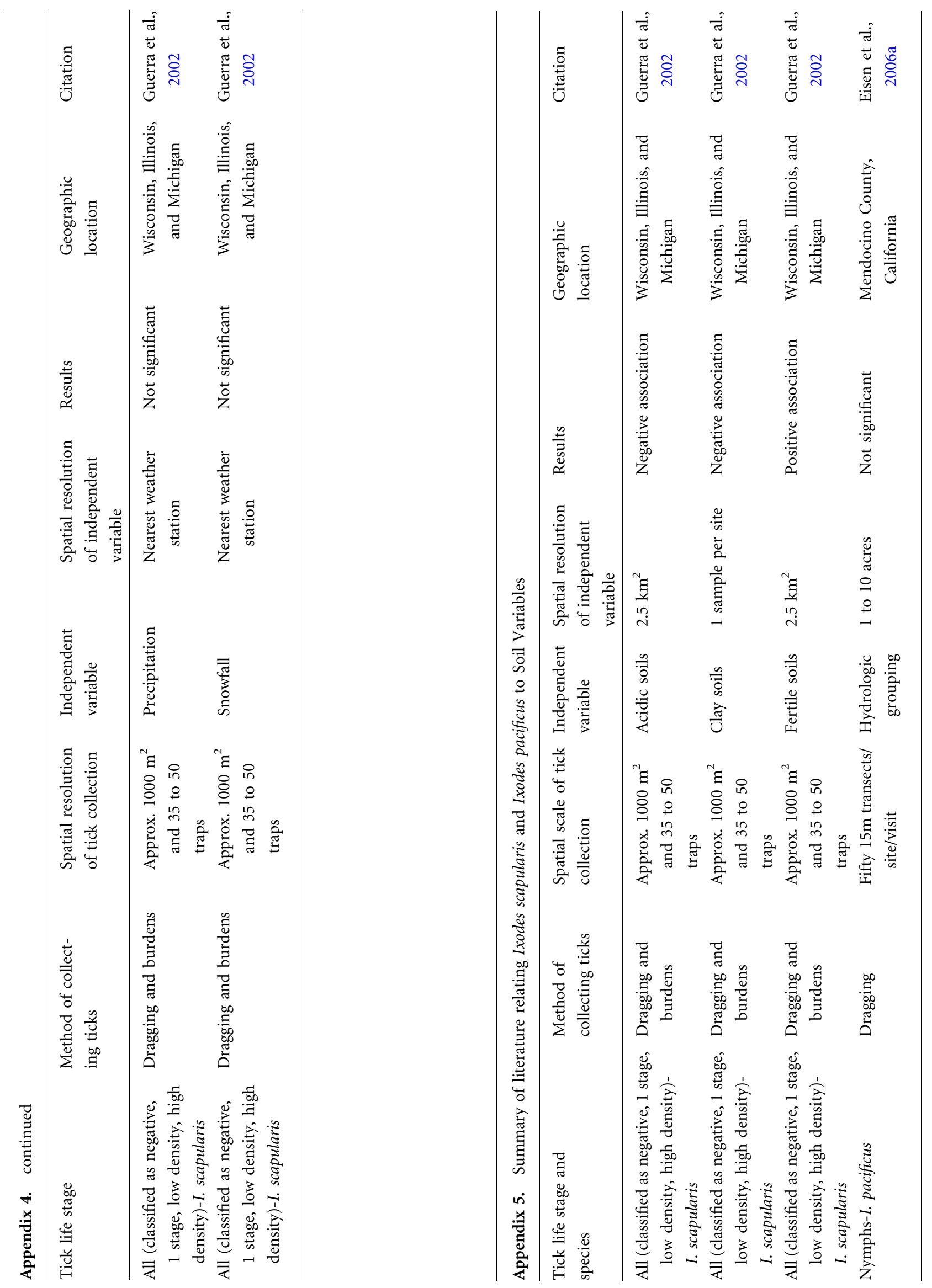


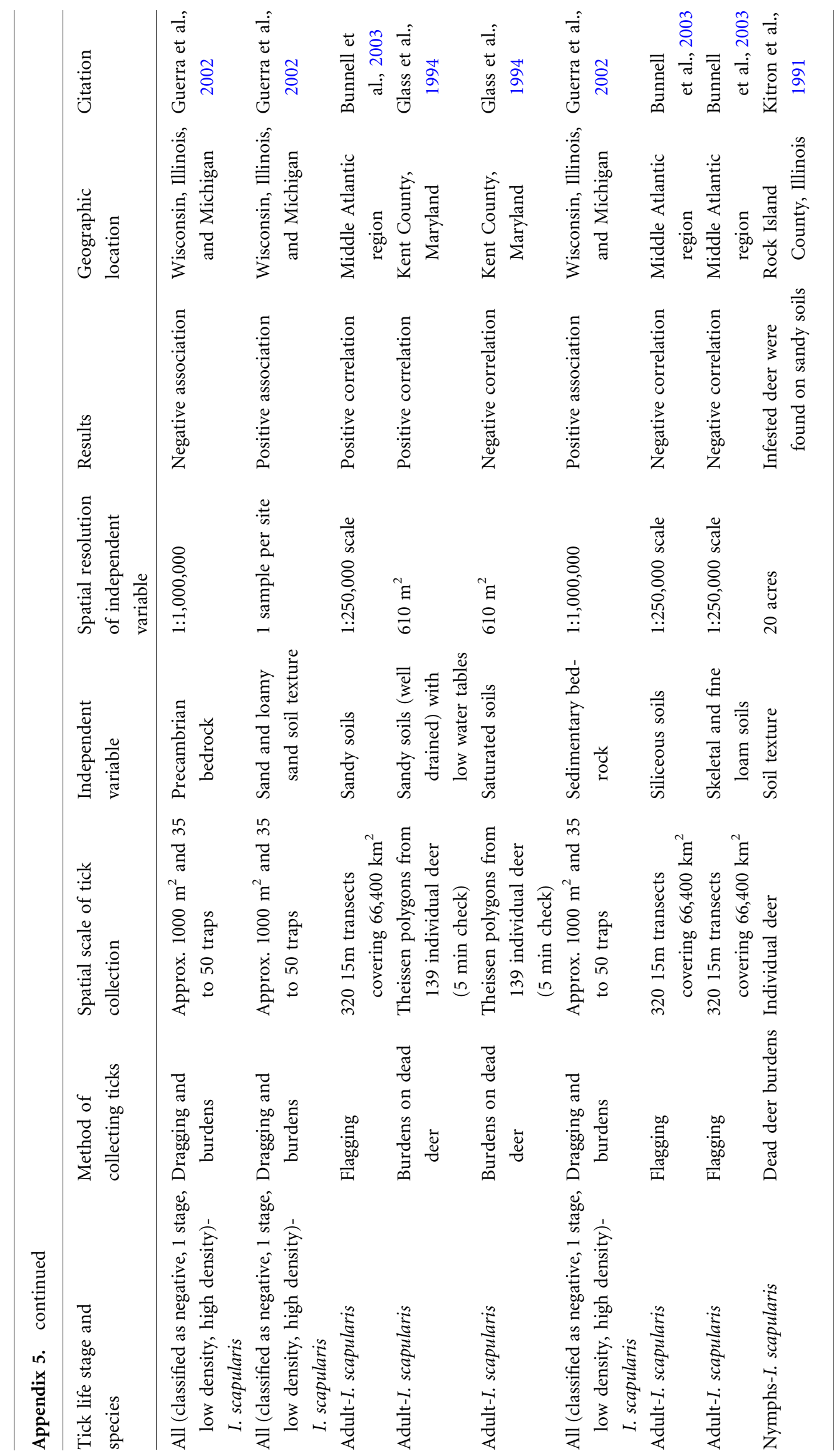




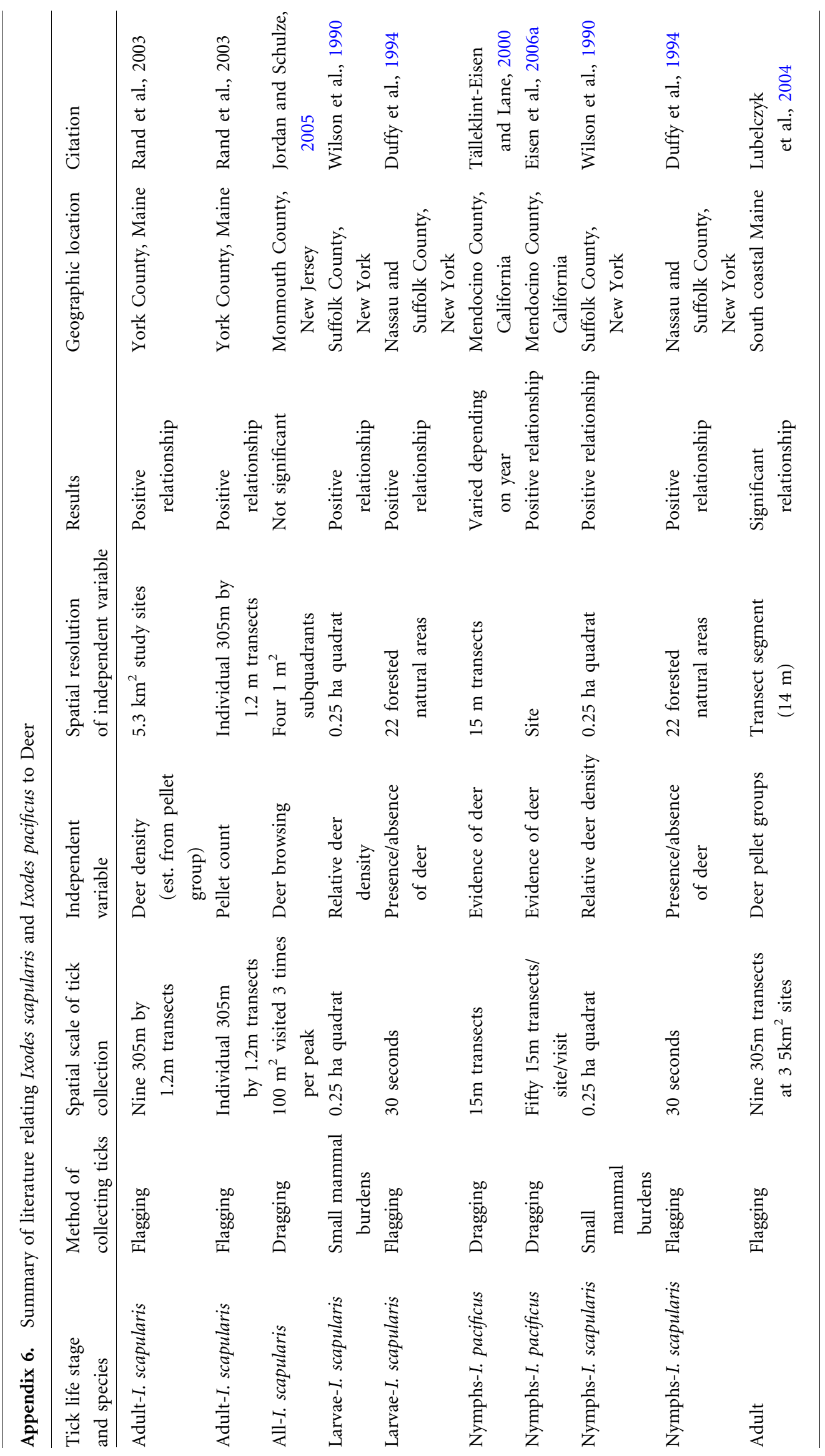




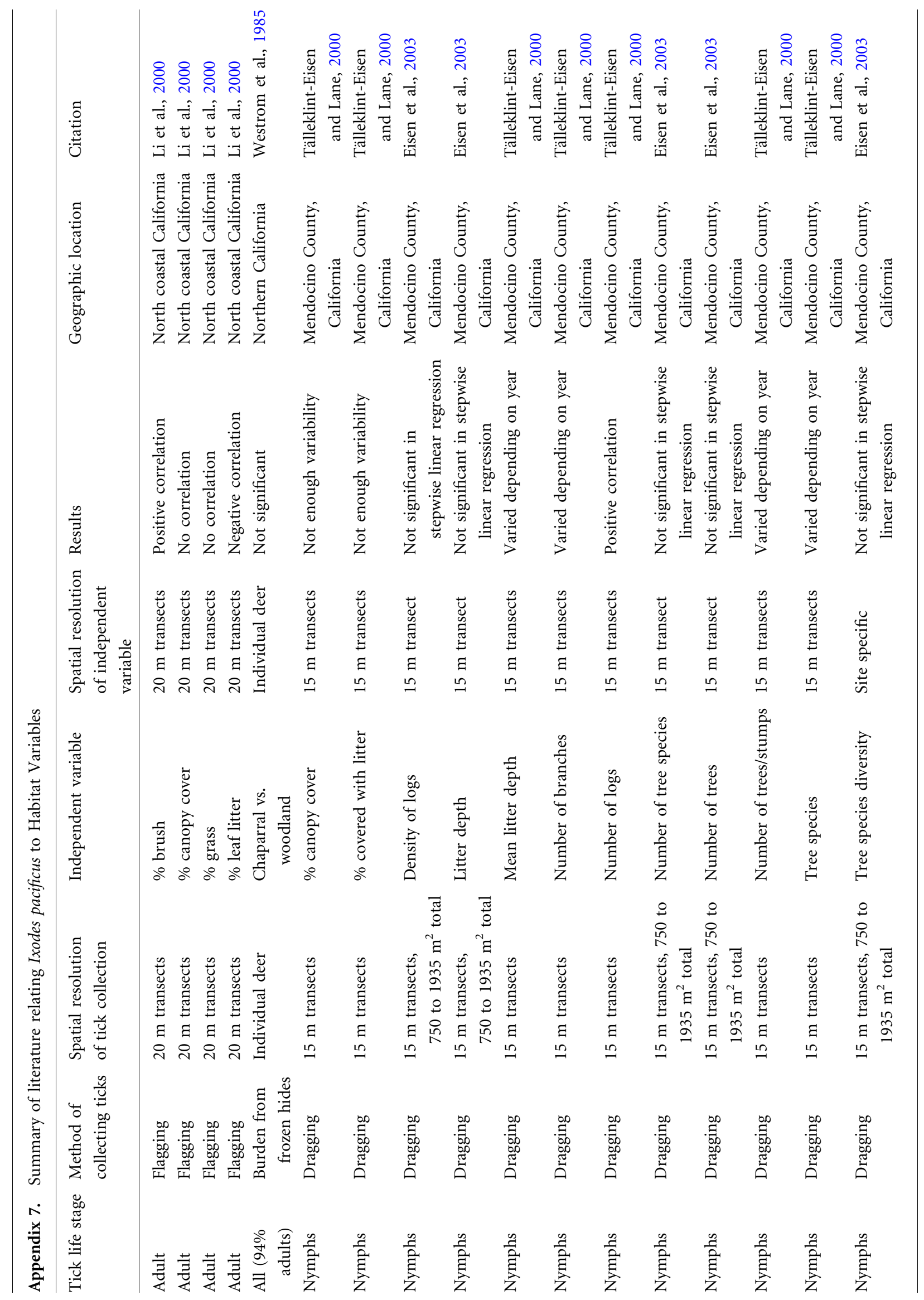



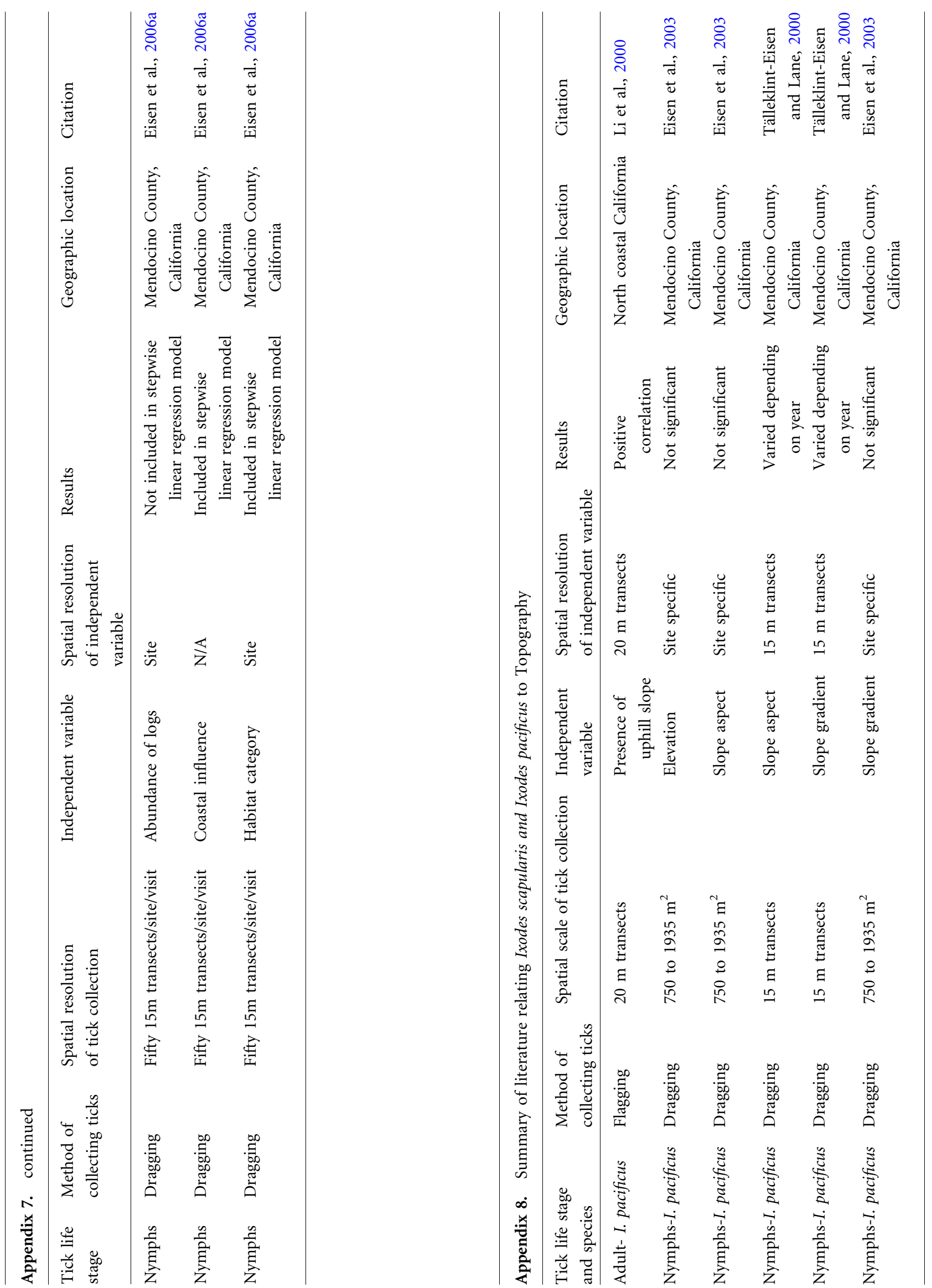


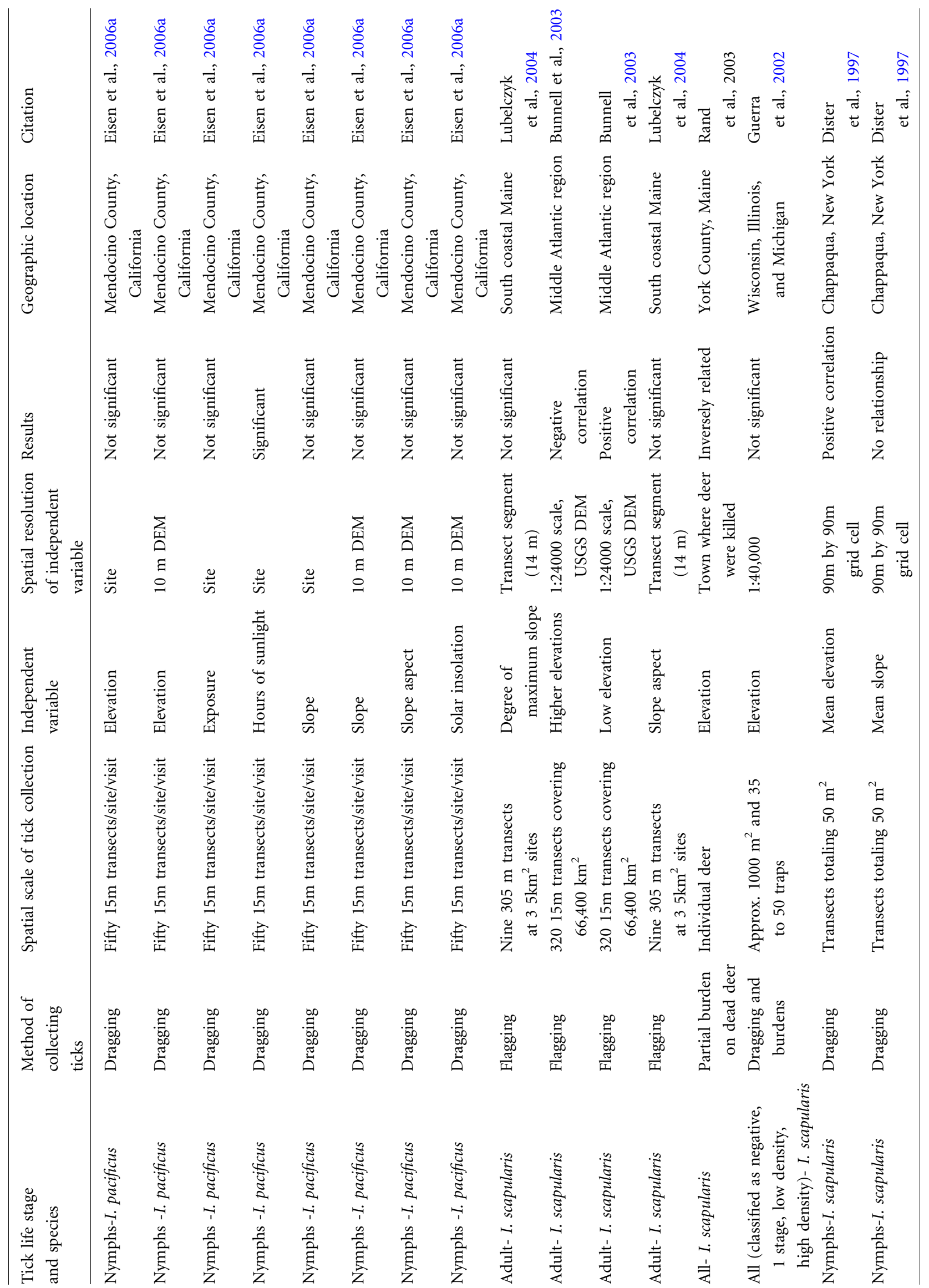




\section{REFERENCES}

Allan BF, Keesing F, Ostfeld RS (2003) Effects of forest fragmentation on Lyme disease risk. Conservation Biology 17:267-272

Amerasinghe FP, Breisch NL, Azad AF, Gimpel WF, Greco M, Neidhardt K, et al. (1992) Distribution, density, and Lyme disease spirochete infection in Ixodes dammini (Acari: Ixodidae) on white-tailed deer in Maryland. Journal of Medical Entomology 29:54-61

Anderson JF, Russell RC, Magnarelli LA, Hyde FW, Myers JE (1987) Prevalence of Borrelia burgdorferi and Babesia microti in mice on islands inhabited by white-tailed deer. Applied and Environmental Microbiology 53:892-894

Belozerov VN (1982) Diapause and biological rhythms in ticks. In: Physiology of Ticks, Obenchain FD, Galun R (editors), New York: Pergamon Press, pp 469-500

Brisson D, Dykhuizen DE, Ostfeld RS (2008) Conspicuous impacts of inconspicuous hosts drive the human Lyme disease epidemic. Proceedings of the Royal Society of London. Series B: Biological Sciences (London)275:227-235

Brown RN, Lane RS (1992) Lyme disease in California: a novel enzootic transmission cycle of Borrelia burgdorferi. Science 256:1439-1442

Brown RN, Lane RS (1996) Reservoir competence of four chaparral-dwelling rodents for Borrelia burgdorferi in California. American Journal of Tropical Medicine and Hygiene 54:84-91

Brownstein JS, Holford TR, Fish D (2003) A climate-based model predicts the spatial distribution of the Lyme disease vector Ixodes scapularis in the United States. Environmental Health Perspectives 111:1152-1157

Brownstein JS, Skelly DK, Holford TR, Fish D (2005) Forest fragmentation predicts local scale heterogeneity of Lyme disease risk. Oecologia 146:469-475

Bunnell JE, Price SD, Das A, Shields TM, Glass GE (2003) Geographic information systems and spatial analysis of adult Ixodes scapularis (Acari: Ixodidae) in the Middle Atlantic region of the USA. Journal of Medical Entomology 40:570-576

Carroll JF, Kramer M (2001) Different activities and footwear influence exposure to host-seeking nymphs of Ixodes scapularis and Amblyomma americanum (Acari: Ixodidae). Journal of Medical Entomology 38:596-600

Centers for Disease Control, Prevention (CDC) (2007) Lyme disease-United States, 2003-2005. Morbidity and Mortality Weekly Report 56:573-576

Chen H, White DJ, Caraco TB, Stratton HH (2005) Epidemic and spatial dynamics of Lyme disease in New York State, 1990-2000. Journal of Medical Entomology 42:899-908

Connally NP, Ginsberg HS, Mather TN (2006) Assessing peridomestic entomological factors as predictors for Lyme disease. Journal of Vector Ecology 31:364-370

Cromley EK, Cartter ML, Mrozinski RD, Ertel SH (1998) Residential setting as a risk factor for Lyme disease in a hyperendemic region. American Journal of Epidemiology 147:472-477

Daniel M, Danielová V, Kríz B, Jirsa A, Nozicka J (2003) Shift of the tick Ixodes ricinus and tick-borne encephalitis to higher altitudes in Central Europe. European Journal of Clinical Microbiology and Infectious Disease 22:327-328

Dennis DT, Hayes EB (2002) Epidemiology of Lyme borreliosis. In: Lyme Borreliosis Biology, Epidemiology and Control, Gray JS, Kahl O, Lane RS, Stanek G (editors), New York: CABI Publishing, pp 251-280
Dennis DT, Nekomoto TS, Victor JC, Paul WS, Piesman J (1998) Reported distribution of Ixodes scapularis and Ixodes pacificus (Acari: Ixodidae) in the United States. Journal of Medical Entomology 35:629-638

Dister SW, Fish D, Bros SM, Frank DH, Wood BL (1997) Landscape characterization of peridomestic risk for Lyme disease using satellite imagery. American Journal of Tropical Medicine and Hygiene 57:687-692

Duik-Wasser MA, Gatewood AG, Cortinas MR, Yaremych-Hamer S, Tsao T, Kitron U, et al. (2006) Spatiotemporal patterns of host-seeking Ixodes scapularis nymphs (Acari: Ixodidae) in the United States. Journal of Medical Entomology 43:166-176

Duffy DC, Clark DD, Campbell SR, Gurney S, Perello R, Simon N (1994) Landscape patterns of abundance of Ixodes-scapularis (Acari, Ixodidae) on Shelter Island, New York. Journal of Medical Entomology 31:875-879

Eisen RJ, Eisen L, Castro MB, Lane RS (2003) Environmentally related variability in risk of exposure to Lyme disease spirochetes in northern California: effect of climatic conditions and habitat type. Environmental Entomology 32:1010-1018

Eisen RJ, Eisen L, Lane RS (2001) Prevalence and abundance of Ixodes pacificus immatures (Acari: Ixodidae) infesting western fence lizards (Sceloporus occidentalis) in northern California: temporal trends and environmental correlates. Journal of Parasitology 87:1301-1307

Eisen RJ, Eisen L, Lane RS (2006) Predicting density of Ixodes pacificus nymphs in dense woodlands in Mendocino County, California, based on geographic information systems and remote sensing versus field-derived data. American Journal of Tropical Medicine and Hygiene 74:632-640

Eisen RJ, Lane RS, Fritz CL, Eisen L (2006) Spatial patterns of Lyme disease risk in California based on disease incidence data and modeling of vector-tick exposure. American Journal of Tropical Medicine and Hygiene 75:669-676

Estrada-Peña A (2001) Distribution, abundance, and habitat preferences of Ixodes ricinus (Acari: Ixodidae) in northern Spain. Journal of Medical Entomology 38:361-370

Estrada-Peña A (2002) Increasing habitat suitability in the United States for the tick that transmits Lyme disease: a remote sensing approach. Environmental Health Perspectives 110:635-640

Falco RC, Fish D (1988) Prevalence of Ixodes dammini near the homes of Lyme disease patients in Westchester County, New York. American Journal of Epidemiology 127:826-830

Fix AD, Peña CA, Strickland GT (2000) Racial differences in reported Lyme disease incidence. American Journal of Epidemiology 152:756-759

Frank DH, Fish D, Moy FH (1998) Landscape features associated with Lyme disease risk in a suburban residential environment. Landscape Ecology 13:27-36

Glass GE, Amerasinghe FP, Morgan JM, Scott TW (1994) Predicting Ixodes-scapularis abundance on white-tailed deer using geographic information-systems. American Journal of Tropical Medicine and Hygiene 51:538-544

Glass GE, Schwartz BS, Morgan JM, Johnson DT, Noy PM, Israel E (1995) Environmental risk-factors for Lyme-disease identified with geographic information-systems. American Journal of Public Health 85:944-948

Glavanakov S, White DJ, Caraco T, Lapenis A, Robinson GR, Szymanski BK, et al. (2001) Lyme disease in New York State: spatial pattern at a regional scale. American Journal of Tropical Medicine and Hygiene 65:538-545 
Goddard J (1992) Ecological studies of adult Ixodes scapularis in central Mississippi: questing activity in relation to time of year, vegetation type and meteorological conditions. Journal of Medical Entomology 29:501-506

Gray JS, Kahl O, Janetzki C, Stein J (1992) Studies on the ecology of Lyme disease in a deer forest in County Galway, Ireland. Journal of Medical Entomology 29:915-920

Guerra M, Walker E, Jones C, Paskewitz S, Cortinas MR, Stancil A, et al. (2002) Predicting the risk of Lyme disease: habitat suitability for Ixodes scapularis in the north central United States. Emerging Infectious Diseases 8:289-297

Horobik V, Keesing F, Ostfeld RS (2006) Abundance and Borrelia burgorferi-infection prevalence of nymphal Ixodes scapularis ticks along forest-field edges. EcoHealth 3:232-238

Jackson LE, Hilborn ED, Thomas JC (2006) Towards landscape design guidelines for reducing Lyme disease risk. International Journal of Epidemiology 35:315-322

Jackson LE, Levine JF, Hilborn ED (2006) A comparison of analysis units for associating Lyme disease with forest edge habitat. Community Ecology 7:189-197

Jensen PM, Hansen H, Frandsen F (2000) Spatial risk assessment for Lyme borreliosis in Denmark. Scandanavian Journal of Infectious Disease 32:545-550

Jordon RA, Schulze TL (2005) Deer browsing and the distribution of Ixodes scapularis (Acari: Ixodidae) in central New Jersey forests. Environmental Entomology 34:801-805

Jouda F, Perret J, Gern L (2004) Ixodes ricinus density, and distribution and prevalence of Borrelia burgdorferi sensu lato infection along an altitudinal gradient. Journal of Medical Entomology 41:162-169

Kitron U, Kazmierczak JJ (1997) Spatial analysis of the distribution of Lyme disease on Wisconsin. American Journal of Epidemiology 145:558-566

Kitron U, Bouseman JK, Jones CJ (1991) Use of the Arc Info GIS to study the distribution of Lyme-disease ticks in an Illinois county. Preventive Veterinary Medicine 11:243-248

Knelle W, Rudolph D (1982) Humidity relationships and water balance of ticks. In: Physiology of Ticks, Obenchain FD, Galun R (editors), New York: Pergamon, pp 43-70

Lane RS (1990) Susceptibility of western fence lizard (Sceloporus occidentalis) to the Lyme borreliosis spirochete (Borrelia burgdorferi). American Journal of Tropical Medicine and Hygiene 42:75-82

Lane RS, Brown RN (1991) Wood rats and kangaroo rats: potential reservoirs of the Lyme disease spirochete in California. Journal of Medical Entomology 28:299-302

Lane RS, Loye JE (1989) Lyme disease in California: interrelationship of Ixodes pacificus (Acari: Ixodidae), the western fence lizard (Sceloporus occidentalis), and Borrelia burgdorferi. Journal of Medical Entomology 26:272-278

Lane RS, Quistad GB (1998) Borreliacidal factor in the blood of the western fence lizard (Scelaporus occidentalis). The Journal of Parasitology 84:29-34

Lane RS, Mun J, Eisen RJ, Eisen L (2005) Western gray squirrel (Rodential: Sciuridae): a primary reservoir host of Borrelia burgdorferi in California oak woodlands? Journal of Medical Entomology 42:388-396

Lane RS, Peavey CA, Padgett KA, Hendson M (1999) Life history of Ixodes (Ixodes) jellisoni (Acari: Ixodidae) and its vector competence for Borrelia burgdorferi sensu lato. Journal of Medical Entomology 36:329-340
Lane RS, Piesman J, Burgdorfer W (1991) Lyme borreliosis: relation of its causative agent to its vectors and hosts in North America and Europe. Annual Review of Entomology 36:587-609

Lane RS, Steinlein DB, Mun J (2004) Human behaviors elevating exposure to Ixodes pacificus (Acari: Ixodidae) nymphs and their associated bacterial zoonotic agents in a hardwood forest. Journal of Medical Entomology 41:239-248

Li X, Peavey CA, Lane RS (2000) Density and spatial distribution of Ixodes pacificus (ACARI: IXODIDAE) in two recreational areas in north coastal California. American Journal of Tropical Medicine and Hygiene 62:415-422

Lindgren E, Jaenson TGT (2006) Lyme Borreliosis in Europe: Influences of Climate and Climate Change, Epidemiology, Ecology and Adaptation Measures, Copenhagen, Denmark: World Health Organization, pp 34

Lindgren E, Tälleklint L, Polfeldt T (2000) Impact of climatic change on the northern latitude limit and population density of the disease-transmitting European tick Ixodes ricinuns. Environmental Health Perspectives 108:119-123

LoGiudice K, Ostfeld RS, Schmidt KA, Keesing F (2003) The ecology of infectious disease: effects of host diversity and community composition on Lyme disease risk. Proceeding of the National Academy of Sciences 100:567-571

Lubelczyk CB, Elias SP, Rand PW, Holman MS, Lacombe EH, Smith RP Jr (2004) Habitat associations of Ixodes scapularis (Acari: Ixodidae) in Maine. Environmental Entomology 33:900906

Mannelli A, Kitron U, Jones CJ, Slajchert TL (1994) Influence of season and habitat on Ixodes scapularis infestation on whitefooted mice in northwestern Illinois. Journal of Parisitology 80:1038-1042

Mather TN, Wilson ML, Moore SI, Ribeiro JMC, Speilman A (1989) Comparing the relative potential of rodents as reservoirs of the Lyme disease spirochete (Borrelia burdoreri). American Journal of Epidemiology 130:143-150

Maupin GO, Fish D, Zultowsky J, Campos EG, Piesman J (1991) Landscape ecology of Lyme disease in a residential area of Westchester County, New York. American Journal of Epidemiology 133:1105-1113

McCabe GJ, Bunnell JE (2004) Precipitation and the occurrence of Lyme disease in the northeastern United States. Vector-borne and Zoonotic Diseases 4:143-148

McEnroe WD (1977) The restriction of the species range of Ixodes scapularis, say, in Massachusetts by fall and winter temperature. Acarologia 18:618-625

McEnroe WD (1984) Winter survival and spring breeding by the fall tick, Ixodes dammini, in Massachusetts (Acarina: Ixodidae). Acarologia 25:223-229

Naleway AL, Belongia EA, Kazmierczak JJ, Greenlee RT, Davis JP (2002) Lyme disease incidence in Wisconsin: a comparison of state-reported rates and rates from a population-based cohort. American Journal of Epidemiology 155:1120-1127

Ogden NH, Digras-Poulin M, O'Callaghan CJ, Barker IK, Lindsay LR, Maarouf A, et al. (2005) A dynamic population model to investigate effects of climate on geographic range and seasonality of the tick Ixodes scapularis. International Journal of Parasitology 35:375-389

Ogden NH, Maarouf A, Barker IK, Bigras-Poulin M, Lindsay LR, Morshed MG, et al. (2006) Climate change and the potential for range expansion of the Lyme disease vector Ixodes scapularis in Canada. International Journal for Parasitology 36:63-70 
Orloski KA, Campbell GL, Genese CA, Beckley JW, Schriefer ME, Spitalny KC, et al. (1998) Emergence of Lyme disease in Hunterdon County, New Jersey, 1993: a case-control study of risk factors and evaluation of reporting patterns. American Journal of Epidemiology 147:391-397

Orloski KA, Hayes EB, Campbell GL, Dennis DT (2000) Surveillance for Lyme disease-United States, 1992-1998. Morbidity and Mortality Weekly Report 49:1-11

Ostfeld RS, Keesing F (2000) Biodiversity and disease risk: the case of Lyme disease. Conservation Biology 14:722-728

Ostfeld RS, Canham CD, Oggenfuss K, Winchcombe RJ, Keesing F (2006) Climate, deer, rodents, and acorns as determinants of variation in Lyme-disease risk. PLoS Biology 4:1058-1068

Ostfeld RS, Cepeda OM, Hazler KR, Miller MC (1995) Ecology of Lyme disease-habitat associations of ticks (Ixodes-scapularis) in a rural landscape. Ecological Applications 5:353-361

Ostfeld RS, Glass GE, Keesing F (2005) Spatial epidemiology: an emerging (or re-emerging) discipline. Trends in Ecology \& Evolution 20:328-336

Padgett KA, Lane RS (2001) Life cycle of Ixodes pacificus (Acari: Ixodidae): timing of developmental processes under field and laboratory conditions. Journal of Medical Entomology 38:684693

Peavey CA, Lane RS (1995) Transmission of Borrlia burgdorferi by Ixodes pacificus nymphs and reservoir competence of deer mice (Peromyscus maniculatus) infected by tick-bite. Journal of Parasitology 81:175-178

Perkins SE, Cattadori IM, Tagliapietra V, Rizzoli AP, Hudson PJ (2006) Localized deer absence leads to tick amplification. Ecology 87:1981-1986

Prusinski MA, Chen H, Drobnack JM, Kogut SJ, Means RG, Howard JJ, et al. (2006) Habitat structure associated with Borrelia burgdorferi prevalence in small mammals in New York State. Environmental Entomology 35:308-319

Racz GR, Ban E, Ferenczi E, Berencsi G (2006) A simple spatial model to explain the distribution of human tick-borne encephalitis cases in Hungary. Vector-borne and Zoonotic Diseases 6:369-378

Randolph SE (2001) The shifting landscape of tick-borne zoonoses: tick-borne encephalitis and Lyme borreliosis in Europe. Philosophical Transactions of the Royal Society of London. Series B: Biological Sciences (London) 356:1045-1056

Rand PW, Lubelczyk C, Lavigne GR, Elias S, Holman MS, Lacombe EH, Smith RP Jr (2003) Deer density and the abundance of Ixodes scapularis (Acari: Ixididae). Journal of Medical Entomology 40:179-184

Rodgers SE, Mather TN (2006) Evaluating satellite sensor-derived indices for Lyme disease risk prediction. Journal of Medical Entomology 43:337-343
Rodgers SE, Zolnik CP, Mather TN (2007) Duration of exposure to suboptimal atmospheric moisture affects nymphal blacklegged tick survival. Journal of Medical Entomology 44:372-375

Schauber EM, Ostfeld RS, Evans AS (2005) What is the best predictor of annual Lyme disease incidence: weather, mice or acorns? Ecological Applications 15:575-586

Schulze TL, Jordan RA, Hung RW (2001) Potential effects of animal activity on the spatial distribution of Ixodes scapularis and Amblyomma americanum (Acari: Ixodidae). Environmental Entomology 30:568-577

Stafford KC, Magnarelli LA (1993) Spatial and temporal patterns of Ixodes-scapularis (Acari, Ixodidae) in southeastern Connecticut. Journal of Medical Entomology 30:762-771

Subak S (2003) Effects of climate on variability in Lyme disease incidence in the northeastern United States. American Journal of Epidemiology 157:531-538

Tälleklint-Eisen L, Lane RS (2000) Spatial and temporal variation in the density of Ixodes pacificus (Acari: Ixodidae) nymphs. Environmental Entomology 29:272-280

Waller LA, Goodwin BJ, Wilson ML, Ostfeld RS, Marshall SL, Hayes EB (2007) Spatio-temporal patterns in county-level incidence and reporting of Lyme disease in the northeastern United States, 1990-2000. Environmental and Ecological Statistics 14:83-100

Westrom DR, Lane RS, Anderson JR (1985) Ixodes pacificus (Acari: Ixodidae): population dynamics and distribution on Columbian black-tailed deer (Odocoileus hemionus columbianus). Journal of Medical Entomology 22:507-511

Wilson ML, Adler GH, Speilman A (1985) Correlation between abundance of deer and that of the deer tick, Ixodes dammini (Acari: Ixodidae). Annals of the Entomological Society of America 78:172-176

Wilson ML, Ducey AM, Litwin TS, Gavin TA, Speilman A (1990) Microgeographic distribution of immature Ixodes dammini ticks correlated with that deer. Medical and Veterinary Entomology 4:151-159

Wilson ML, Telford SRI, Piesman J, Speilman A (1988) Reduced abundance of immature Ixodes dammini (Acari: Ixodidae) following removal of deer. Journal of Medical Entomology 25:224228

Wright SA, Lane RS, Clover JR (1998) Infestation of the southern alligator lizard (Squamata: Anguidae) by Ixodes pacificus (Acari: Ixodidae) and its susceptibility to Borrelia burgdorferi. Journal of Medical Entomology 35:1044-1049 